\title{
Three-Dimensional Elastomeric Scaffolds Designed with Cardiac-Mimetic Structural and Mechanical Features
}

\author{
Rebekah A. Neal, PhD, , Aurélie Jean, PhD, ${ }^{2}$ Hyoungshin Park, PhD, ${ }^{1,3}$ \\ Patrick B. Wu, BS, ${ }^{1}$ James Hsiao, BS, ${ }^{3}$ George C. Engelmayr, Jr., PhD, ${ }^{4}$ \\ Robert Langer, ScD, and Lisa E. Freed, MD, PhD ${ }^{1,3}$
}

Tissue-engineered constructs, at the interface of material science, biology, engineering, and medicine, have the capacity to improve outcomes for cardiac patients by providing living cells and degradable biomaterials that can regenerate the native myocardium. With an ultimate goal of both delivering cells and providing mechanical support to the healing heart, we designed three-dimensional (3D) elastomeric scaffolds with (1) stiffnesses and anisotropy mimicking explanted myocardial specimens as predicted by finite-element (FE) modeling, (2) systematically varied combinations of rectangular pore pattern, pore aspect ratio, and strut width, and (3) structural features approaching tissue scale. Based on predicted mechanical properties, three scaffold designs were selected from eight candidates for fabrication from poly(glycerol sebacate) by micromolding from silicon wafers. Large $20 \times 20 \mathrm{~mm}$ scaffolds with high aspect ratio features (5:1 strut height:strut width) were reproducibly cast, cured, and demolded at a relatively high throughput. Empirically measured mechanical properties demonstrated that scaffolds were cardiac mimetic and validated FE model predictions. Two-layered scaffolds providing fully interconnected pore networks were fabricated by layer-by-layer assembly. C2C12 myoblasts cultured on onelayered scaffolds exhibited specific patterns of cell elongation and interconnectivity that appeared to be guided by the scaffold pore pattern. Neonatal rat heart cells cultured on two-layered scaffolds for 1 week were contractile, both spontaneously and in response to electrical stimulation, and expressed sarcomeric $\alpha$-actinin, a cardiac biomarker. This work not only demonstrated several scaffold designs that promoted functional assembly of rat heart cells, but also provided the foundation for further computational and empirical investigations of 3D elastomeric scaffolds for cardiac tissue engineering.

\section{Introduction}

C ARDIOvASCULAR DISEASE remains the leading cause of death in the United States and other developed countries and is a tremendous public health burden, with $\$ 297.7$ billion in direct and indirect costs in 2008 in the United States alone. ${ }^{1}$ In addition to myocardial infarction (MI) and other acquired cardiomyopathies, approximately one percent of newborns and an increasing number of adults around the world survive with congenital heart disease, a condition associated with extremely high morbidity. ${ }^{2}$ Many of these patients could benefit from more effective cardiac grafts to replace tissue damaged by infarct or malformed at birth. Current pharmacological and prosthetic-based interventions serve either to modulate or to replace dysfunctional tissue; cellularized scaffolds capable of mediating endogenous tis- sue regeneration have yet to be adopted clinically. In general, conventional cardiovascular prostheses such as synthetic vascular grafts, ${ }^{3}$ bioprosthetic heart valves, ${ }^{4}$ and cardiac support, patch, or plug devices ${ }^{5-7}$ are capable of ameliorating disease and routinely improve patient outcomes, quality of life, and life expectancy. However, without living cells, bioprosthetic devices have limited potential to recapitulate the full breadth of native tissue functions or to support new tissue growth, which is especially important for pediatric applications. Recent studies suggest that an actively contractile graft could perform better than a simpler, nonviable implant. $^{8,9}$

Tissue-engineered constructs comprised of living cells cultivated within a wide variety of scaffolds, including biomaterials with three-dimensional (3D) pore architectures, ${ }^{10-12} 3 \mathrm{D}$ gels, ${ }^{13-17}$ composite scaffolds, ${ }^{18-21}$ and de novo synthesized ${ }^{22-24}$

\footnotetext{
${ }^{1}$ Harvard-MIT Division of Health Sciences and Technology, David H. Koch Institute for Integrative Cancer Research, and Institute for Medical Engineering and Science, Massachusetts Institute of Technology, Cambridge, Massachusetts.

${ }^{2}$ Department of Aeronautics and Astronautics, Massachusetts Institute of Technology, Cambridge, Massachusetts.

${ }^{3}$ Microsystems Development and MEMS Fabrication Groups, Charles Stark Draper Laboratory, Cambridge, Massachusetts.

${ }^{4}$ Department of Biomedical Engineering, Duke University, Durham, North Carolina.
} 
or decellularized ${ }^{25}$ extracellular matrices, offer a potential alternative, ${ }^{26}$ and have shown promising results in both animal $^{12,25,27,28}$ and human ${ }^{29-31}$ studies in helping to resolve diverse cardiovascular lesions. By varying the material of construction and the fabrication method, scaffold mechanical properties may be controllable over a broad range. Nevertheless, many of the scaffolds utilized in these constructs lack the specific structural and mechanical requirements necessary within the cardiac regeneration environment.

The design and implementation of a clinically effective and durable scaffold remain a critical unmet need in cardiovascular medicine, where combining elasticity, porosity, and strength have been particularly challenging. ${ }^{32}$ In particular, the optimal mechanical properties of a scaffold designed to repair infarcted myocardium remain an unresolved question. If the scaffold is intended solely as a vehicle for cells to allow more effective cell delivery than simple injection of dissociated cells, then scaffold mechanical properties should accommodate robust cell viability, proliferation, and differentiation before and after engraftment. Scaffolds designed with this intent could compromise relatively soft, naturally occurring or engineered biomaterials, with stiffnesses shown to optimally support maturation and synchronous, auxotonic contractility of cardiomyocytes, 33,34 and capable of delivering cells in combination with bioactive factors. ${ }^{14,15,35,36}$ However, if the scaffold is further intended to provide myocardial reinforcement after infarction, then scaffold mechanical properties will likely derive from a balance of considerations, addressing not only effective cell delivery but also infarct location and timing of the intervention. In particular, distinct collagenous scar tissue anisotropies were shown to evolve in different infarct locations ${ }^{37}$ as part of a complex healing process, ${ }^{38}$ warranting customized anisotropic reinforcement strategies that have been explored by computational analysis ${ }^{39}$ and demonstrated in vivo. ${ }^{40}$ An early example of a scaffold designed with the dual intent of delivering cells and providing mechanical reinforcement explored the combination of fibrin gel and an anisotropic elastomeric knitted fabric made of hyuloronan benzyl ester. ${ }^{19}$

As the material of construction for scaffolds fabricated in the present study, we selected a unique synthetic bioresorbable elastomer poly(glycerol sebacate) (PGS), developed by Wang et al., ${ }^{41}$ and recently reviewed by Rai et al. ${ }^{42}$ PGS, the 1:1 molar polycondensate of naturally occurring metabolites glycerol and sebacic acid, reproduces synthetically the mechanical stiffness and elasticity of the collagen and elastin components of the extracellular matrix. PGS provokes minimal inflammatory response, ${ }^{43-45}$ can be relatively hemocompatible, ${ }^{46}$ has compliant, elastomeric mechanical properties tunable to those of native tissues, ${ }^{11,47,48}$ and is supportive of cardiogenesis ${ }^{11,20,49}$ and vascular elastogenesis. ${ }^{50}$ Moreover, PGS degrades primarily by surface hydrolysis, ${ }^{43,44}$ with relative preservation of scaffold form and function, thereby facilitating the computational design of scaffolds exhibiting predictable cell guidance and load-bearing capacities upon tissue evolution and PGS degradation. ${ }^{51-53}$

We previously showed that microfabricated PGS scaffolds of low-to-moderate stiffnesses $(\sim 30-300 \mathrm{kPa})$ exhibited mechanical stability and supported the in vitro cultivation and synchronous contraction of cultured rat heart cells, although in a manner that was largely isometric under the conditions tested. ${ }^{11,20}$ With an ultimate goal of both delivering cells and providing mechanical support to the healing heart in the present study, we sought to design, develop, and demonstrate a set of PGS scaffolds with (1) elastomeric stiffness and mechanical anisotropy mimicking native myocardium, (2) systematically varied combinations of rectangular pore pattern, pore aspect ratio, and strut width, and (3) microfabricated structural features approaching tissue scale. To match scaffold mechanical properties to native myocardium entailed considering the directional dependence, or anisotropy. ${ }^{8,38}$ To achieve minimal resistance to cyclic contraction and stretch, we chose PGS because it maintained elastic behavior during cyclic loading tests and heart cell culture in vitro, ${ }^{11}$ and showed promise as a myocardial implant material in vivo. ${ }^{54-56}$ We undertook finite-element (FE) modeling of a systematically varied set of eight scaffold designs from which we selected three scaffolds, based on cardiac mimetic mechanical properties, for fabrication and demonstration in a $3 \mathrm{D}$ in vitro model of engineered cardiac tissue. To enable fabrication of structural and geometrical features approaching tissue scale at a relatively high throughput, we chose replica molding as a method by which we could create precise, reproducible, microporous architectures in a variety of shapes and patterns.

\section{Materials and Methods}

\section{Silicon mold fabrication}

Silicon wafer molds were fabricated as previously described, with modifications. ${ }^{51}$ Mold designs were laid out using L-Edit (Tanner). CAD/ART Services (Brandon) generated Mylar mask transparencies with a laser photo-plotter (Orbotech 7008, 20,000 dpi). Four-inch-diameter silicon wafers were used as the base for generating scaffold molds (WRS Materials). Hexamethyldisilazane, a photoresist adhesion promoter, was applied via spin-coating $(4000 \mathrm{rpm}$, $30 \mathrm{~s}$ ) and baked on a hotplate at $95^{\circ} \mathrm{C}$ for $60 \mathrm{~s}$. Shipley $1822-$ positive photoresist was then applied via spin-coating (4000 rpm, $30 \mathrm{~s}$ ) to achieve a $2.4-\mu \mathrm{m}$-thick coating, and baked in an oven at $92^{\circ} \mathrm{C}$ for $30 \mathrm{~min}$. An MA-6 Photo Aligner (Suss Microtech, Inc.) applied hard-contact UV exposure for $9 \mathrm{~s}$. Wafers underwent a $55 \mathrm{~s}$ developing step in Microposit MF319 (Microchem Corp.), and then were rinsed in dI- $\mathrm{H}_{2} \mathrm{O}$ and spun dry. Wafers were then cleaned briefly in a March PX-250 Plasma Asher (March Plasma Systems) at 55 W for $5 \mathrm{~min}$, followed by an oven hard-bake step at $110^{\circ} \mathrm{C}$ for $30 \mathrm{~min}$. Exposed silicon was etched in a Surface Technology Systems Inductively Coupled Plasma Etcher (STS-ICP), targeting 50-, 100-, and 150- $\mu \mathrm{m}$ depths. Photoresist was stripped by oxygen plasma (100 W, $5 \mathrm{~min})$, followed by SVC-14 photoresist stripper (Rohn \& Haas) for $20 \mathrm{~min}$. Wafers were cleaned in a piranha bath $\left(1: 1 \mathrm{H}_{2} \mathrm{SO}_{4}: \mathrm{H}_{2} \mathrm{O}_{2} ; 20 \mathrm{~min}\right)$, rinsed, and spun-dry. To improve release from the mold by reducing sidewall roughness and sharp corners, wafers with 100and $150-\mu \mathrm{m}$ etch depth were subjected to a 10-to-20-min isotropic silicon etch in an STS-Reactive Ion Etch (STS RIE). After oxygen plasma treatment $(100 \mathrm{~W}, 20 \mathrm{~min})$, another piranha cleaning was performed, after which the wafers were stored until use. Clean wafers were spin-coated with maltose $\left(70 \%\right.$ in $\left.\mathrm{dd}-\mathrm{H}_{2} \mathrm{O}\right)$ in a two-step coating process (1000 rpm, $10 \mathrm{~s} ; 3000 \mathrm{rpm}, 30 \mathrm{~s}$ ) on a CEE100 spinner (Brewer 
Science). ${ }^{57}$ The spun maltose was baked on a hotplate at $95^{\circ} \mathrm{C}$ for $5 \mathrm{~min}$, and coated wafers were stored with a desiccant at room temperature until use. For reuse, wafers were again cleaned using a piranha bath, rinsed, dried, and recoated with maltose.

\section{PGS synthesis and scaffold fabrication}

PGS prepolymer was synthesized as previously described. ${ }^{11,58}$ Briefly, prepolymer was synthesized by reacting glycerol and sebacic acid in a 1:1 molar ratio under heat and vacuum for $72 \mathrm{~h}$. For curing, prepolymer was dissolved in 200 Proof ethanol at 50\% (w/v), and cast volumetrically into maltose-coated silicon molds fitted with poly(dimethyl siloxane) (PDMS) gaskets. Volumes were adjusted to produce either open-through pores that extended from top surface to bottom surface or closed pores bounded by a thin PGS film. Wafers were heated to $110^{\circ} \mathrm{C}$ for $30 \mathrm{~min}$ to allow ethanol to evaporate, and then the prepolymer was cured under vacuum (10-15 mTorr) at $160^{\circ} \mathrm{C}$ for $6 \mathrm{~h}$. Scaffolds and nonporous membranes were demolded by soaking in dI- $\mathrm{H}_{2} \mathrm{O}$ at $60^{\circ} \mathrm{C}-$ $70^{\circ} \mathrm{C}$ for 1 to 3 days to dissolve the maltose sacrificial layer. Scaffolds were air-dried for use in characterization experiments or autoclave-sterilized $\left(121^{\circ} \mathrm{C}, 30 \mathrm{~min}\right)$ and then soaked in a serum-containing culture medium for 5 to 8 days before use in cell culture studies. To prepare two-layered (2L) scaffolds, two one-layered (1L) scaffolds were stacked and bonded as previously described, ${ }^{20}$ with the top layer containing through pores and the bottom layer bounded by a thin PGS film on the lower surface. The long axes of the pores were aligned and offset by half the pore length to yield stacked scaffolds exhibiting two layers of interconnected pores. Manual alignment of the scaffolds was challenging due to the small size of the pores and deformation of the elastomeric PGS, especially evident with the 5:1 cubic rectangular (CR) scaffolds. To achieve bonding, interior surfaces were subjected to oxygen plasma (100 W, 120 s), aligned by eye under a stereomicroscope (Nikon SMZ1500; Nikon), and compressed under a weight $(200 \mathrm{~g})$ for $16 \mathrm{~h}$ at room temperature. To prepare 2L scaffolds with a PGS thin film across the bottom for cell retention, a $1 \mathrm{~L}$ scaffold with film was placed film side down, treated with oxygen plasma along with a $1 \mathrm{~L}$ scaffold with through pores, and the plasmatreated sides were bonded together using the method described. 2L scaffolds were examined dry to assess the successful layer-to-layer alignment, or autoclaved and prepared for cell culture as described for 1L scaffolds.

\section{Scaffold characterization: scanning electron microscopy and mechanical testing}

Samples were prepared for scanning electron microscopy (SEM) by sputter coating with gold-palladium (108auto sputter coater; Cressington Scientific Instruments) for $30 \mathrm{~s}$. Samples were then mounted either flat, or at 45 degrees, within a Hitachi S3500 SEM (Hitachi High Technologies America), and imaged using 5-kV accelerating voltage. Measurements of scaffold dimensions were made using the measure tool in ImageJ. ${ }^{59}$ For uniaxial tensile mechanical testing, standardized specimens were prepared using a dogbone punch (gauge length $5 \mathrm{~mm}$; width $2 \mathrm{~mm}$ ), and thicknesses were measured with a spring-loaded dial gauge (L.S. Starrett Co). Samples were cut from dry, 1L scaffolds with through pores, fitted with $5 \times 5 \mathrm{~mm}$ paper apertures to set gauge length and assist in holding samples in mounts without tearing, and mounted on an Electroforce ELF 3200 mechanical tester (Bose) fitted with a $250 \mathrm{~g}$ load cell (Sensotech, Inc.), and controlled with WinTest software. Samples were strained to failure using a ramp speed of $0.1 \mathrm{~mm} / \mathrm{s}(2 \%$ strain/s). Orthogonal material directions were tested with independent samples: parallel (PD) or perpendicular (XD) to the long axis of the pore structure. For each test direction, effective stiffnesses $\left(E_{\mathrm{PD}}\right.$ and $\left.\mathrm{E}_{\mathrm{XD}}\right)$ were calculated from the slope of the stress-strain curve between 1\% and 10\% strain, and anisotropy, $r$, was calculated as the $\mathrm{E}_{\mathrm{PD}} / \mathrm{E}_{\mathrm{XD}}$ ratio. Strain-to-failure $\left(\varepsilon f_{\mathrm{PD}}\right.$ and $\left.\varepsilon \mathrm{f}_{\mathrm{XD}}\right)$ data were also collected from the stress-strain curve.

\section{C2C12 cell culture}

To examine the capacity of the three patterns to promote cell elongation and interconnectivity, C2C12 myoblasts were cultured on scaffolds for 5 days. C2C12 myoblasts elongate readily in culture, making this a good cellular model for preliminary studies of the effect of scaffold architecture on elongation. ${ }^{51} \mathrm{C} 2 \mathrm{C} 12$ cells were obtained from the American Type Culture Collection (ATCC) and maintained in a complete culture medium consisting of the Dulbecco's modified Eagle's medium supplemented with $10 \%$ fetal bovine serum and $1 \%$ penicillin/streptomycin (pen/strep). 1L scaffolds with through pores were punched to 5-mm-diameter discs and preincubated in a culture medium as described, dried gently by blotting with sterile gauze, and placed in sterile 12-well dishes with one scaffold per well. Cells were seeded onto scaffolds (50,000 cells/ $30 \mu \mathrm{L}$ culture medium per scaffold) and allowed to attach for $45 \mathrm{~min}$. Then, an additional $2 \mathrm{~mL}$ of medium was added, and constructs were cultured for 5 days. Media were completely replaced every 2 days, and constructs were harvested on culture day 5 .

\section{Heart cell isolation and culture}

Heart cells were isolated from neonatal rats (aged 1 to 2 days) following an Institutional Animal Care and Use Committee-approved protocol, as previously described. ${ }^{20}$ Briefly, hearts were harvested, and ventricle tissue was isolated, minced, and digested overnight in a trypsin solution $\left(1 \mathrm{mg} / \mathrm{mL}\right.$; Sigma) at $4^{\circ} \mathrm{C}$. After trypsin digestion, cells were serially digested using type II collagenase solution (1 mg/ $\mathrm{mL}$; Worthington Biochemical Corp.) until dissociated into a single cell-suspension. Dissociated cells were preplated for $1 \mathrm{~h}$ in tissue culture flasks to enrich for cardiomyocytes, and cells that remained unattached to the flask were used to seed scaffolds. This preplating method has been characterized to yield a cell population containing $63 \% \pm 2 \%$ cardiomyocytes, $33 \% \pm 3 \%$ cardiac fibroblasts, $3 \%$ to $4 \%$ smooth muscle cells, and $2 \%$ to $3 \%$ endothelial cells, ${ }^{60}$ and has previously been successful in our hands at producing viable, contractile cultures. ${ }^{20}$ For cell seeding, 2L scaffolds bounded by a thin PGS film were punched into $5-\mathrm{mm}$ discs, preincubated in a culture medium as described, dried gently by blotting, and placed within PDMS gaskets (6- to 7-mm inner diameter; 1- to 2-mm high) in 12-well tissue culture plates. Heart cells were seeded onto scaffolds (3.5 million cells $/ 50 \mu \mathrm{L}$ of culture medium per scaffold). Immediately thereafter, an additional 
$2 \mathrm{~mL}$ of medium was added slowly to avoid disturbing the heart cells within the gasket, and constructs were placed in a standard incubator. Gaskets were left in place for at least $24 \mathrm{~h}$, to allow time for gravitational cell settling into the pores and initial cell binding to the scaffolds; gaskets were removed after 24 to $48 \mathrm{~h}$ to mitigate adverse effects on diffusion of a culture medium through the radial surfaces of the constructs. Media were completely replaced every 2 days, and constructs were harvested after 1 week.

\section{Electrophysiology}

Response to electrical field stimulation was assessed for 1-week cardiac constructs as previously described. ${ }^{11,18,20,61,62}$ Briefly, constructs were placed in a custom-designed, environmentally controlled test chamber. The chamber was fitted with two carbon electrodes (1/4-inch diameter; Ladd Research) separated by a distance of $1.5 \mathrm{~cm}$. Constructs were intentionally positioned within the test chamber such that the scaffold PD was aligned in parallel to the stimulating electrodes and covered with $10 \mathrm{~mL}$ of $37^{\circ} \mathrm{C}$ culture medium. Platinum wire leads connected the electrodes to an electrical pulse generator $($ S $88 \times$ Dual Output Square Pulse Stimulator; Grass Technologies), which was used to apply monophasic square pulses with 2-ms duration and 1-Hz frequency. Initial voltage was set at $1 \mathrm{~V}$ and ramped in $0.5 \mathrm{~V}$ increments until each stimulus solicited a matching contraction in the construct. This voltage was recorded as the excitation threshold (ET). Contractions were observed and video imaged on a Zeiss Axiovert inverted microscope (Zeiss), at $10 \times$ magnification.

\section{Histology}

After electrophysiological testing, and for samples not used for electrophysiology, constructs were rinsed gently with phosphate-buffered saline (PBS), fixed in $10 \%$ neutral buffered formalin overnight at $4^{\circ} \mathrm{C}$, rinsed several times in PBS, and stored in fresh PBS at $4^{\circ} \mathrm{C}$ in preparation for histological assessments.

To assess cardiomyocyte presence and marker expression, constructs seeded with heart cells were permeabilized with $0.1 \%$ Triton $\mathrm{X}-100$, blocked with $0.1 \%$ bovine serum albumin (BSA), stained with sarcomeric $\alpha$-actinin primary antibody overnight (1:500; Sigma), followed by fluorescein-conjugated anti-mouse IgG secondary antibody (2 h, 1:200; Vector Lab), counterstained with DRAQ5 nuclear stain (1:200; Axxora LLC), and examined using an MICF-Nikon 1AR Ultra-Fast Spectral Scanning Laser Confocal Microscope with NIS Elements Acquisition Software (Nikon). To assess muscle cell elongation and interconnectivity, constructs seeded with C2C12 cells were permeabilized and blocked as described, then stained for filamentous actin (f-actin) using fluorescein isothiocyanate (FITC)-phalloidin conjugate (1:40; Sigma), counterstained with DRAQ5 nuclear stain, and examined using the confocal microscope. To assess cell distribution within constructs seeded with heart cells, constructs were bisected, embedded in Tissue Tek O.C.T Compound (Sakura Finetek), and frozen for cross sectioning on a Thermo Shandon Cryotome SME (Thermo Scientific). Sixty- $\mu$ m-thick sections were cut, stained with hematoxylin and eosin (H\&E; Sigma), and imaged on a Zeiss Axiovert inverted microscope (Zeiss) to evaluate cellular infiltration into the scaffold.

\section{FE modeling}

Extending our recently described method, ${ }^{52,53}$ an FE periodic model was used to predict the effective stiffnesses and anisotropy ratio of scaffolds with varying pore pattern, pore length, and strut width. The FE model was developed using Z-set software (ZSet Resources, Mines ParisTech, ONERA, NWNumerics, http://zebulon.onera.fr/English/index.html). Briefly, scaffolds were designed as periodic tessellations defined by the translation of a unit cell along vectors of periodicity. The unit cell comprised void space in the shape of the pore surrounded by PGS with width equal to one-half the scaffold strut width, with axes of symmetry along the PD and XD directions. Periodic, homogeneous boundary conditions were prescribed on the unit cell to compute the effective stiffnesses of the heterogeneous structure (i.e., structure comprising PGS struts and void pore space). For the PGS phase, the elastic modulus ( $\left.E_{P G S}\right)$ was assigned based on mechanical test data, assuming that the PGS material exhibited isotropic linear elastic behavior for strain $<10 \% .{ }^{11,51,58}$ For the void space, an elastic modulus near zero $(0.0001 \mathrm{MPa})$ was assigned to obtain a condition number amenable to stiffness matrix inversion during the FE code execution; for both phases, a Poisson's ratio equal to 0.45 was assumed. $^{52}$ The FE model was also used to model degradation of the scaffold. Since PGS degrades by surface hydrolysis, strut width is expected to decrease while the pore area is expected to increase concomitantly over time. To ascertain the effects of this surface hydrolysis-dominated degradation on $\mathrm{E}_{\mathrm{PD}}, \mathrm{E}_{\mathrm{XD}}$, and $r$, the model was applied over a decreasing range of strut widths with concomitant increase in pore area and a constant PGS-effective stiffness; PGS bulk hydrolysis was assumed to be negligible. The FE model was also used to simulate macroscopic loading of the scaffold, as previously described. ${ }^{52}$

\section{Statistical analysis}

For mechanical testing, statistical significance was assessed in Minitab 15 Statistical Software (Minitab Inc.) using a general linear model analysis of variance (ANOVA) with two fixed, crossed factors (pore pattern and test direction) with Tukey's post hoc testing to establish among- and between-group significance. Significance was asserted at $p<0.05$. Statistical differences in ET were assessed using Minitab 15 Statistical Software with a one-way ANOVA and Tukey's post hoc testing with significance asserted at $p<0.05$.

\section{Results}

\section{Scaffold design}

Two pore patterns were considered, CR and hexagonal rectangular (HR), indicating four or six first-neighbor pores respectively (Fig. 1). FE modeling of the tensile mechanical properties of two patterns (CR and HR), two aspect ratios (2:1 and 5:1 pore length: pore width, $L / l)$, and two strut widths $(\mathrm{w}, 30$ and $50 \mu \mathrm{m})$ provided a blueprint for selecting three scaffold designs for fabrication (Fig. 1) from a total of eight possible combinations of pore pattern, pore aspect ratio, and strut width (Table 1). With an ultimate goal of both delivering cells and providing mechanical support to the healing heart, our scaffold design goals were to meet dual objectives of microfabricating structural features approaching tissue scale and matching scaffold mechanical properties 


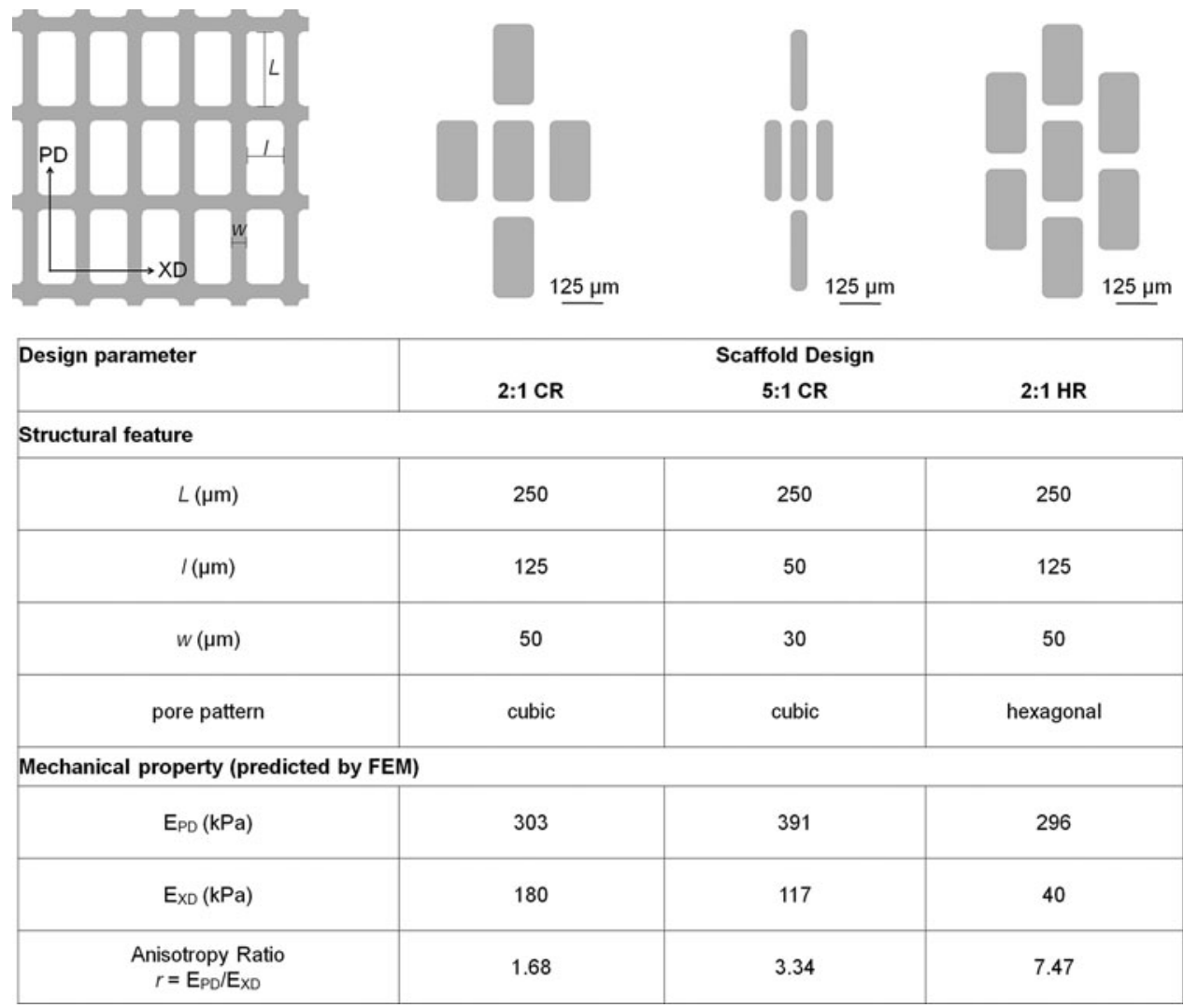

FIG. 1. Three scaffold designs were selected for fabrication, 2:1 cubic rectangular (2:1 CR), 5:1 cubic rectangular (5:1 CR), and 2:1 hexagonal rectangular $(2: 1$ HR). The cubic and hexagonal pore patterns, respectively, refer to the existence of four or six firstneighbor pores. The 2:1 and $5: 1$ aspect ratio pores refer to the ratio of long-pore length:short-pore length, $L / l$, while $w$ refers to the strut width. The three scaffold designs were chosen for best comparison between structural features and matching of effective stiffnesses predicted by the finite-element (FE) model to those previously measured for normal adult rat left ventricular (LV) myocardium. to physiological values for elastomeric stiffness and anisotropy, properties that depend on cardiac structure and strongly influence pumping function.

As a starting point to select target scaffold structural features, we modeled pore inner dimensions $(L, l)$ previously fabricated by laser microablation of PGS membranes, ${ }^{11,20,51}$ and minimum strut widths $(w)$ deemed to be technically achievable. Rectangular pore shape was selected based on empirical evidence that this pore shape was mechanically anisotropic and was capable of aligning fibroblasts and their collagenous matrix ${ }^{63}$ and muscle cells. ${ }^{11,51}$ For modeling

Table 1. Mechanical Properties Were Predicted For Candidate Scaffold Designs

\begin{tabular}{|c|c|c|c|c|c|}
\hline \multicolumn{3}{|c|}{ Scaffold Design } & \multicolumn{3}{|c|}{ Predicted Mechanical Properties } \\
\hline Symmetry & $\begin{array}{c}\text { aspect } \\
\text { ratio }\end{array}$ & $\begin{array}{l}\text { strut width } \\
\quad(\mu m)\end{array}$ & $\begin{array}{l}E_{P D} \\
(k P a)\end{array}$ & $\begin{array}{c}E_{X D} \\
(k P a)\end{array}$ & $\begin{array}{c}r\left(E_{P D} /\right. \\
\left.E_{X D}\right)\end{array}$ \\
\hline \multirow[t]{4}{*}{ Cubic } & $2: 1$ & 50 & 303.13 & 180.40 & 1.68 \\
\hline & & 30 & 198.74 & 111.75 & 1.78 \\
\hline & $5: 1$ & 50 & 549.28 & 193.51 & 2.84 \\
\hline & & 30 & 391.74 & 117.34 & 3.34 \\
\hline \multirow[t]{4}{*}{ Hexagonal } & $2: 1$ & 50 & 296.31 & 39.65 & 7.47 \\
\hline & & 30 & 196.10 & 11.09 & 17.68 \\
\hline & $5: 1$ & 50 & 519.91 & 25.18 & 20.65 \\
\hline & & 30 & 379.88 & 6.00 & 63.30 \\
\hline
\end{tabular}

Of eight possible combinations of two pore patterns (cubic and hexagonal), two pore aspect ratios (2:1 and 5:1) and two strut widths (50 and $30 \mu \mathrm{m}$ ), three scaffold designs (shaded and bold-face) were selected based on best comparison between structural features and matching of predicted mechanical properties $\left(\mathrm{E}_{\mathrm{PD}}, \mathrm{E}_{\mathrm{XD}}\right.$, and $\left.r\right)$ to those of normal adult rat left ventricular (LV) myocardium. purposes, the bulk PGS stiffness, $E_{\text {PGS, was prescribed as }}$ $791 \pm 58 \mathrm{kPa}$ (mean \pm SEM, $n=6)$, as empirically measured for nonporous, $112 \pm 21-\mu \mathrm{m}$-thick PGS membranes cured at 10 to 15 mTorr and $160^{\circ} \mathrm{C}$ for $6 \mathrm{~h}$. FE simulations of PGS scaffold mechanical properties were run with minimum, maximum, and mean values of $E_{P G S}$ to predict scaffold-effective stiffnesses in two orthogonal directions, $E_{\mathrm{PD}}$ and $\mathrm{E}_{\mathrm{XD}}$. These values were used to predict anisotropy, $r$, as the ratio of $\mathrm{E}_{\mathrm{PD}} /$ $\mathrm{E}_{\mathrm{XD}}$. For selection of target scaffold mechanical properties, we used ranges measured for explanted rectangular specimens of normal adult rat left ventricular myocardium (LV) harvested in two orthogonal directions (circumferential and longitudinal). ${ }^{20}$ We reasoned scaffold mechanical properties $\left(\mathrm{E}_{\mathrm{PD}}, \mathrm{E}_{\mathrm{XD}}\right.$, and $r$ ) should recapitulate LV stiffnesses in the two orthogonal directions $(157 \pm 43 \mathrm{kPa}$ and $84 \pm 23 \mathrm{kPa}$, mean \pm SD of $n=9$ specimens) and the corresponding LV anisotropy ratio $(r=1.87)$. Of note, this anisotropy ratio offers only a partial measure of anisotropy of the scaffold, considering only the directions relevant to direct comparison between the scaffold and LV.

Three scaffold designs (Fig. 1) were selected from FE model output data for all eight possible combinations of pore pattern, pore aspect ratio, and strut width (Table 1) for their predicted consistency with physiological data in $\mathrm{E}_{\mathrm{PD}}, \mathrm{E}_{\mathrm{XD}}$, and $r$, and for best comparison to one another. Of the four CR designs considered, 2:1 CR with 50- $\mu \mathrm{m}$ struts and 5:1 CR with $30-\mu \mathrm{m}$ struts were chosen to bracket the targeted value for anisotropy ratio (Table 1, rows 1 and 4). Comparing 2:1 $\mathrm{CR}$ and 5:1 CR, feature sizes $(l, w)$ were decreased, but pore pattern was maintained constant, and mechanical properties were maintained within a factor of two (Fig. 1, column 2 vs. 3). Of the four possible HR designs considered, 2:1 HR with 
50- $\mu$ m struts was selected (Table 1 , row 5 ), while the other candidates were discounted for anisotropy ratios far higher than the physiological range (Table 1). Comparing 2:1 CR and 2:1 HR, EXD was decreased, and $r$ was increased by more than four-fold, but $\mathrm{E}_{\mathrm{PD}}$, and the feature size $(L, l, w)$ were maintained constant (Fig. 1, column 2 vs. 4).

\section{Mold and scaffold fabrication}

The chosen designs, 2:1 CR, 5:1 CR, and 2:1 HR, were etched into silicon molds to allow for easily reproducible micromolding, as the same mold may be used indefinitely with appropriate care and cleaning. Pore and strut dimensions of the molds for 2:1 CR and 2:1 HR were identical $(L=250 \mu \mathrm{m}, l=125 \mu \mathrm{m}, w=50 \mu \mathrm{m})$, while for 5:1 CR, the pore and strut dimensions were varied $(L=250 \mu \mathrm{m}, l=50 \mu \mathrm{m}$, $w=30 \mu \mathrm{m})$. Wafer sets were etched to three different depths $(50,100$, and $150 \mu \mathrm{m})$, to extend the range of strut width to strut height that could be reproducibly fabricated.

As compared to previous PGS micromolding efforts, ${ }^{51,58,64,65}$ three methodological improvements were made. First, wafer fabrication included a final RIE step to smooth sharp corners in the molds etched to 100 and $150 \mu \mathrm{m}$ to facilitate demolding of the corresponding PGS scaffolds. Second, a maltose-coating method developed by Wang et $a .^{57}$ replaced sucrose as the sacrificial layer ${ }^{65}$ to reduce concerns of crystallization leading to unintended microarchitecture on the scaffold surfaces. Third, the PGS prepolymer was dissolved in ethanol before casting to provide more reproducible control of scaffold thickness.

FIG. 2. One-layered (1L) poly(glycerol sebacate) (PGS) scaffolds with precisely defined, anisotropic pores were rapidly and reproducibly micromolded from silicon masters. Representative light micrographs (A-C) of etched silicon molds demonstrating three scaffold designs: 2:1 CR (A, D, G, H, I), 5:1 CR (B, E, J, $\mathbf{K}, \mathbf{L})$, and 2:1 HR (C, F). Scanning electron micrographs of PGS scaffolds delaminated from silicon molds illustrate successful pattern replication $(\mathrm{D}-\mathrm{F})$ and full-thickness scaffolds from 50- $\mu \mathrm{m}$ deep (G, J,), 100- $\mu \mathrm{m}$ deep $(\mathbf{H}, \mathbf{K})$, and $150-\mu \mathrm{m}$ deep molds (I, L), viewed from above (D-F) or 45 degrees (G-L). Scaffolds were fabricated either with through pores (G, J, I, L), or with an $\sim 50-\mu \mathrm{m}$-thick PGS film at the base for enhanced cell retention $(\mathbf{H}, \mathbf{K})$, indicated by black arrowheads. Scale bars: $200 \mu \mathrm{m}$.
Large $20 \times 20 \mathrm{~mm}$ PGS scaffolds were cast, cured, and demolded from molds with all three scaffold designs and three thicknesses of 50, 100, and $150 \mu \mathrm{m}$ (Fig. 2). Scaffolds faithfully matched the intended design and retained consistent dimensions after multiple uses of each mold $(l=126.4 \pm 1.6,56.5 \pm 1.2$, and $123.5 \pm 2.4 \mu \mathrm{m} ; L=250.9 \pm 1.3$, $247.0 \pm 1.1$, and $246.5 \pm 2.5 \mu \mathrm{m}$; and $w=41.2 \pm 2.8,22.7 \pm 2.5$, and $46.1 \pm 1.0 \mu \mathrm{m}$ for 2:1 CR, 5:1 CR, and 2:1 HR molds etched to a depth of $100 \mu \mathrm{m}$, respectively). Scaffolds for heart cell culture were fabricated with an $\sim 50-\mu$ m-thick PGS film on one surface to assist in cell retention during seeding and culture (Fig. 2H, K). The 100- $\mu$ m layer height was selected for subsequent studies of scaffold mechanical properties and cell compatibility demonstration, since these $1 \mathrm{~L}$ scaffolds were thick enough to allow for handling, but thin enough to minimize diffusion limitations.

\section{Scaffold mechanical properties}

Average effective stiffnesses of PGS scaffolds tested dry ranged from 273 to $293 \mathrm{kPa}$ for $\mathrm{E}_{\mathrm{PD}}$ and 85 to $179 \mathrm{kPa}$ for $\mathrm{E}_{\mathrm{XD}}$, while lower values were obtained for PGS scaffolds tested after 1 week of immersion in $37^{\circ} \mathrm{C}$ PBS (131 to $206 \mathrm{kPa}$ for $\mathrm{E}_{\mathrm{PD}}$ and 37 to $138 \mathrm{kPa}$ for $\left.\mathrm{E}_{\mathrm{XD}}\right)$. When compared with stiffness values predicted by the FE model, experimentally measured stiffnesses obtained for PGS scaffolds matched closely, and trends were maintained (Fig. 3A). Specifically, model predictions of $\mathrm{E}_{\mathrm{PD}}$ were $11.0 \%, 33.8 \%$, and $3.98 \%$ greater than empirical values and for 2:1 CR, 5:1 CR, and 2:1 $\mathrm{HR}$, respectively. Predictions of $\mathrm{E}_{\mathrm{XD}}$ were $1.06 \%$ greater, and
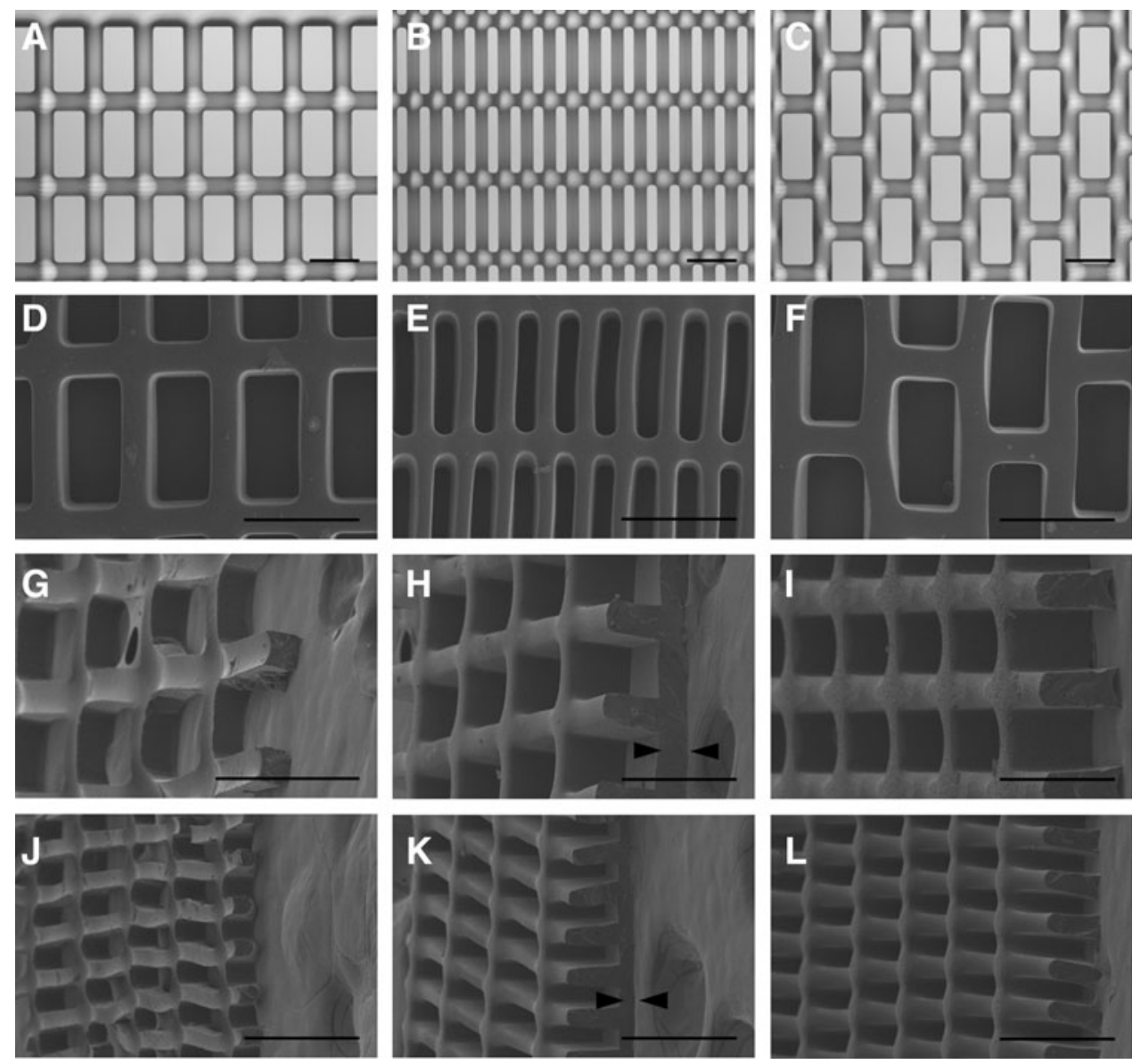

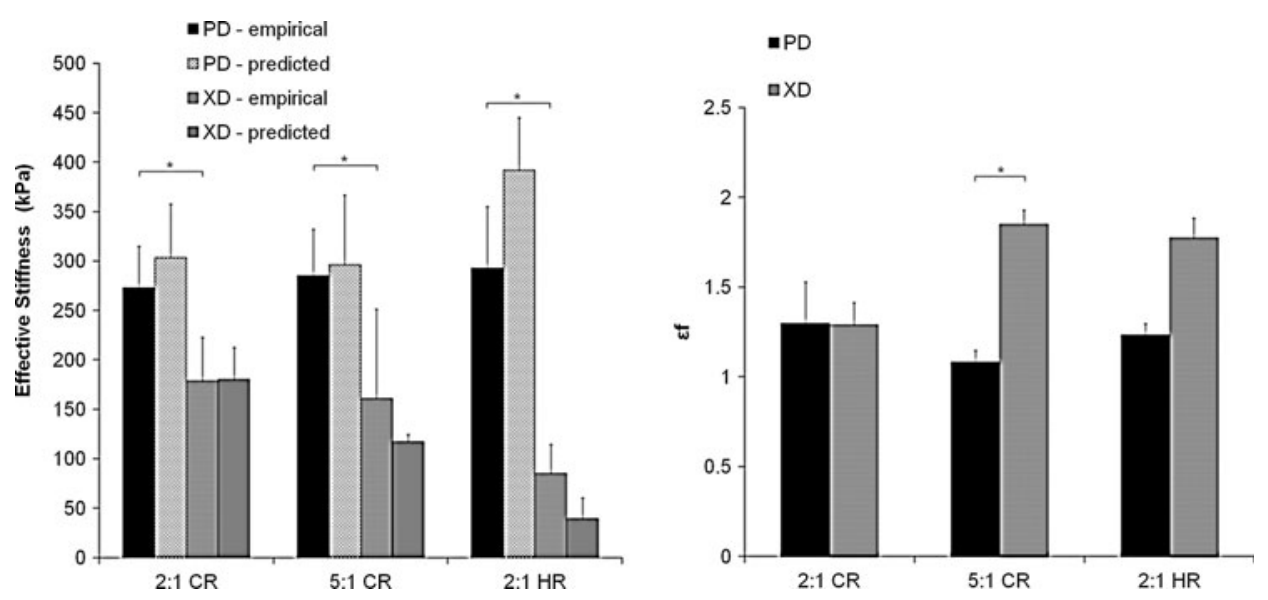

FIG. 3. Scaffolds exhibited elastomeric, anisotropic mechanical properties that closely matched FE model predictions. Orthogonal material directions were tested with independent samples: parallel (PD) or perpendicular (XD) to the long axis of the pore structure. Effective stiffnesses $\left(\mathrm{E}_{\mathrm{PD}}\right.$ and $\left.\mathrm{E}_{\mathrm{XD}} ; \mathrm{kPa}\right)$ were calculated from uniaxial tensile tests and modeled using the FE model (left panel). Strains to failure ( $\varepsilon f_{\mathrm{PD}}$ and $\left.\varepsilon f_{\mathrm{XD}}\right)$ were measured from uniaxial tensile tests to failure (right panel). Empirical data represent the mean \pm standard error of at least three independent measurements. * indicates significant difference between corresponding measurements (i.e., $\mathrm{E}_{\mathrm{PD}}$ vs. $\mathrm{E}_{\mathrm{XD}} ; p<0.05$, and $\varepsilon \mathrm{f}_{\mathrm{PD}} \mathrm{vs}$. $\varepsilon \mathrm{f}_{\mathrm{XD}} ; p=0.011$ ), as determined by ANOVA with Tukey's post hoc testing.

$27.1 \%$ and $53.2 \%$ lesser than empirical values for the same patterns. As predicted, anisotropy was demonstrated, with a significant difference between experimental $\mathrm{E}_{\mathrm{PD}}$ and $\mathrm{E}_{\mathrm{XD}}$ as a whole (all scaffold $\mathrm{E}_{\mathrm{PD}}$ compared to all scaffold $\mathrm{E}_{\mathrm{XD}}$, $p<0.001)$ and for both the 2:1 CR $(p=0.007)$ and 2:1 HR $(p=0.021)$ groups individually. Scaffold pattern alone did not yield significant differences in $E_{P D}$ or $E_{X D}$ across the groups (i.e., $E_{X D}$ measured for 2:1 CR was not significantly different from $E_{X D}$ measured for 5:1 CR). Experimental anisotropy ratios $(r=1.5,1.8$, and 3.4 for 2:1 CR, 5:1 CR, and 2:1 $\mathrm{HR}$, respectively) matched the trends and values predicted by the model ( $r=1.7,3.4,7.5$, respectively). As compared to values previously measured for the LV myocardium, scaffold $E_{P D}$ was higher than physiologic in all three groups; scaffold $E_{X D}$ was higher in the two $C R$ groups and physiologic in the HR group; and scaffold $r$ was lower than physiologic in the 2:1 CR group, physiologic in the 5:1 CR group, and higher than physiologic in the 2:1 HR group. Strain to failure $(\varepsilon f)$ of all three scaffold patterns was greater than one and showed a significant difference between experimental $\mathrm{\varepsilon f}$ in the PD and XD directions $(p=0.0014)$ (Fig. 3B). No significant differences were found among groups for $\varepsilon f_{P D}$ or $\varepsilon f_{X D}$. As compared to previously measured rat LV data $\left(\varepsilon f_{P D}=0.9 \pm 0.1 ; \varepsilon f_{X D}=1.1 \pm 0.2\right),{ }^{20}$ scaffold $\varepsilon f_{P D}$ and scaffold $\varepsilon f_{X D}$ were either similar or slightly higher for all three groups.

The FE model predicted that all the three scaffold designs would exhibit gradual decreases in $\mathrm{E}_{\mathrm{PD}}$ and $\mathrm{E}_{\mathrm{XD}}$ as a function of simulated degradation-mediated decreases in PGS strut width (Fig. 4A-C). Moreover, the model predicted that the anisotropy ratio would increase markedly during degradation of the HR design, particularly as the strut width decreased below $40 \mu \mathrm{m}$ (Fig. 4C), but would be maintained relatively constant, although with slight increases, during degradation of the two CR designs. Simulations further suggested that the 2:1 HR scaffold would respond to mechanical loading in the XD direction principally by flexural deformation of struts oriented in the PD direction (Fig. 4E), while the two CR scaffolds would instead respond to mechanical loading by tensile extension of struts oriented in the XD direction (2:1 CR; Fig. 4D).

\section{C2C12 cells on one-layer scaffolds}

C2C12 cells displayed distinct behaviors when cultured on each of the three pore arrangements (Fig. 5). Cell elongation along the PD-axis was qualitatively visible in the 5:1 CR design, at the top surface of the struts and within the pores (Fig. 5B, E, H), while elongation along the $\mathrm{XD}$-axis was relatively more pronounced in the 2:1 CR design (Fig. 5A, D, G) and elongation along both PD- and XD-axes as well as diagonally between pores was observed in the 2:1 HR design (Fig. 5C, F, I). The direction of cell elongation appeared to correlate with cellular bridging across struts and connecting with cells in neighboring pores.

\section{Heart cells on two-layer scaffolds}

Replica-molded 1L scaffolds were assembled into 2L scaffolds with an underlying thin PGS film by manual stacking with offset pores. The 2L scaffolds exhibited combined thickness of the porous region of the scaffolds measuring $\sim 200-\mu \mathrm{m}$ thick, twice the thickness of 1L scaffolds of the same pattern, while the underlying PGS film was $\sim 50$ $\mu \mathrm{m}$ thick (Fig. 6).

Heart cells began to contract spontaneously after 3 days in culture and continued to do so throughout the 1-week study. After 1 week, scaffolds were subjected to electrical field stimulation to determine the ET, which describes the stimulating voltage required to capture the resultant contraction. Constructs based on all scaffold designs contracted in response to electrical field stimulation (Fig. 7). Although the 5:1 CR design showed lower mean ET than the 2:1 CR design, the difference was not significant ( $p>0.05)$; however, ET was significantly lower for the 2:1 HR design than for the 2:1 CR design $(p=0.042)$. 

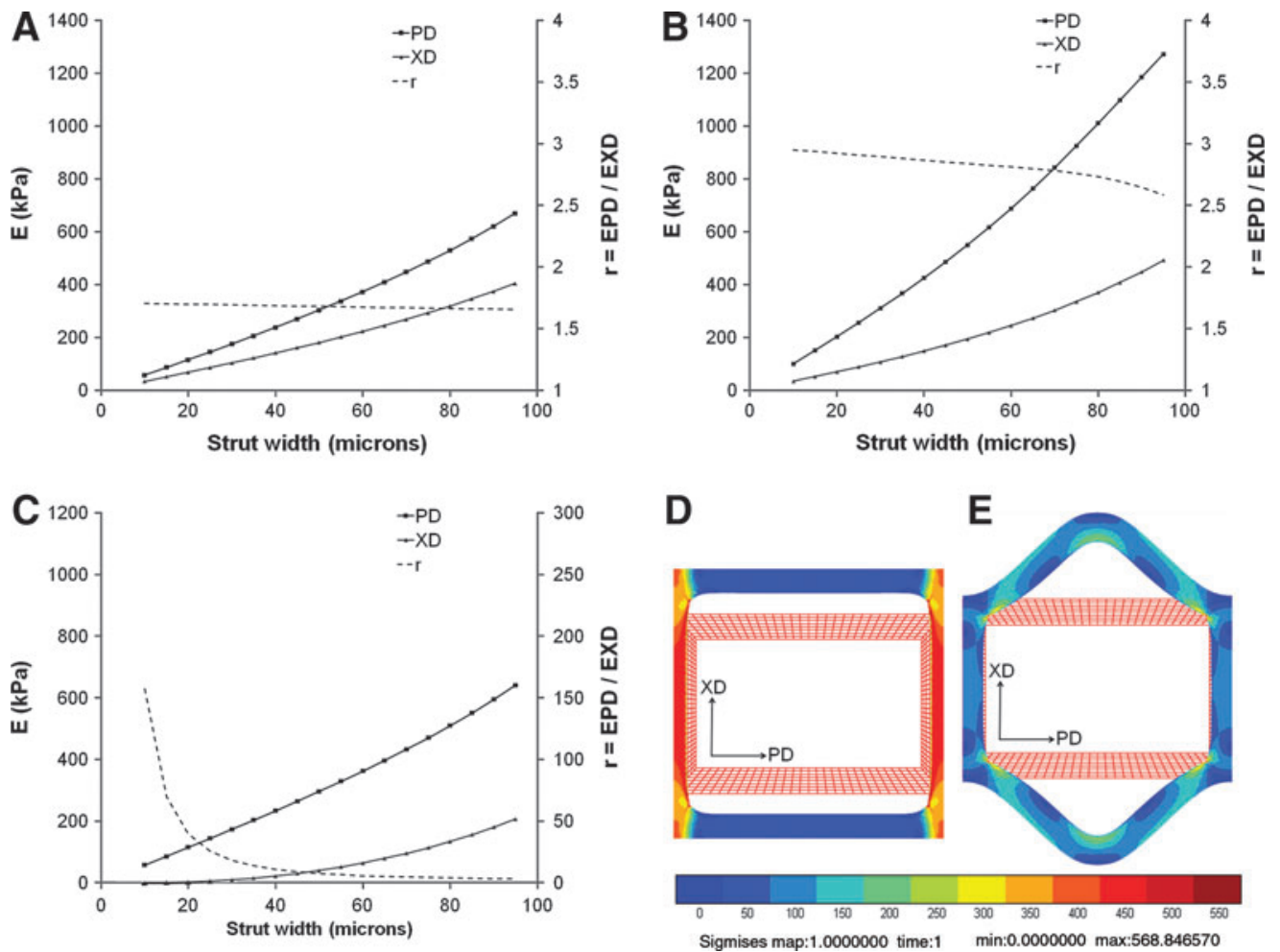

FIG. 4. FE model simulated scaffold degradation. FE model predicted changes in $E_{P D}$ and $E_{X D}$ (E; primary $y$-axes) and anisotropy ratio (r; secondary y-axes) are presented as a function of scaffold strut width for (A) 2:1 CR, (B) 5:1 CR, and (C) 2:1 HR scaffolds. Of note, the strut widths and pore areas of the FE model unit cells describing the scaffold pores were covaried in such a way as to explicitly simulate surface hydrolysis-dominated scaffold degradation. Of note, during simulated tensile loading of scaffolds in the XD direction, models predicted primarily tensile deformation of the XD-oriented struts for the 2:1 CR (D) compared to primarily flexural deformation (i.e., bending) of the PD-oriented struts for the 2:1 HR (E) design. Color images available online at www.liebertpub.com/tea

Cross sections of fixed 1-week samples showed heart cells seeded throughout the full depth of $2 \mathrm{~L}$ scaffolds of all three scaffold designs (Fig. 8A-C), suggesting that the static seeding method used was sufficient for cells to reach the porous areas of at least 2L scaffolds with interconnected pores up to $200-\mu \mathrm{m}$ deep. The 5:1 CR pattern qualitatively yielded the thickest layer of cells across the top strut surfaces, possibly due to the smaller pore size and greater difficulties in manual layer alignment, preventing some pore filling (Fig. 8B inset). Because the heart cell isolation retained cardiac fibroblasts along with the cardiomyocytes, sarcomeric $\alpha$-actinin was used as a specific marker to verify the presence of cardiomyocytes after 1 week in culture. In all three designs, $\alpha$-actinin was prevalent (Fig. 8D-F), and there was some degree of sarcomeric banding (Fig. 8G-I, arrowheads), consistent with the observation of coordinated contractions. While the neonatal heart cells remained predominantly immature and rounded at 1 week, positive immunostaining for $\alpha$-actinin provided evidence of early-stage cardiomyocyte differentiation, and functional responses to electrical stimulation provided evidence of heart cell viability, interconnectivity, and contractility

\section{Discussion}

In this study, we designed, developed, and demonstrated a set of 2L elastomeric PGS scaffolds with offset and fully interconnected pores that provided a platform for cell de- livery while recapitulating the geometry and mechanical properties of normal heart muscle.

Utilizing a structured engineering design plan allowed interrogation of scaffold mechanical properties in a manner directly relevant to the objective of designing scaffolds with biomimetic mechanical properties; others ${ }^{48,66}$ have used a similar approach to scaffold design. Specifically, we developed an FE model describing periodic, tessellated scaffolds with rectangular pores, for probing changes in scaffold stiffness and anisotropy while varying three factors: pore pattern (CR and HR), rectangular aspect ratio (2:1 and 5:1), and strut width $(50 \mu \mathrm{m}$ and $30 \mu \mathrm{m})$. This computational approach helped pare down the scaffolds for fabrication from eight candidates to three cardiac-mimetic options, thereby increasing efficiency and yield while reducing time and expense. While our previous work showed that FE modeling could retrospectively predict empirically determined scaffold mechanical properties, ${ }^{52}$ including the influence of tissue filling the pores, ${ }^{53}$ the present work extended use of FE modeling to intentionally choosing scaffolds that provide the desired architecture, stiffness, and anisotropy, for fabrication and demonstration in a 3D in vitro model of engineered cardiac tissue. As metrics, we selected (1) mechanical matching of the scaffolds to normal rat myocardium (Table 1; Figs. 1, 3 and 4), (2) structural evidence of cell-to-cell connectivity in 1L constructs (Fig. 5), (3) contractile response to electric stimulation in 2L constructs (Fig. 7), (4) heart cell 

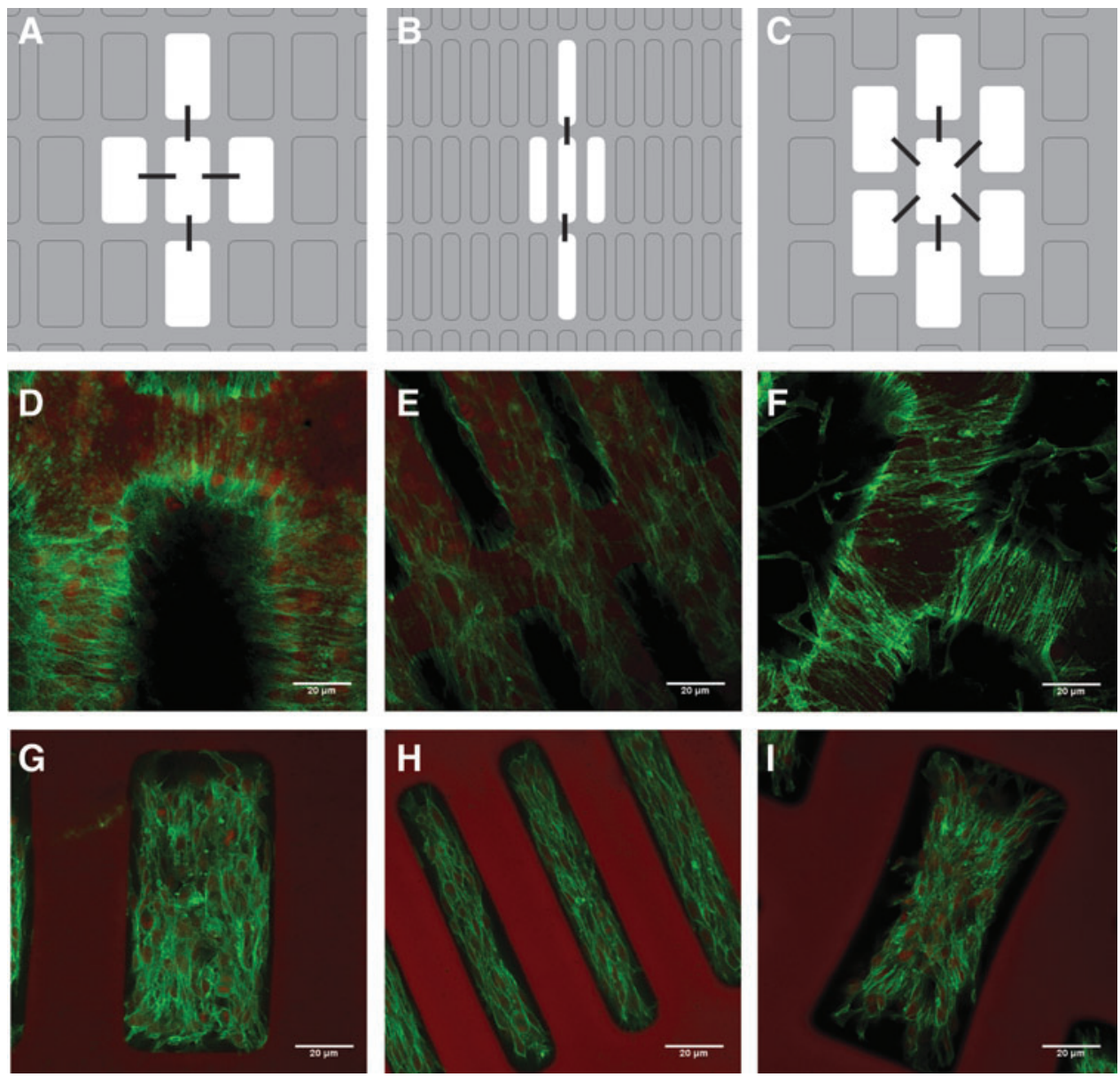

FIG. 5. Scaffold design influenced elongation and interconnectivity of C2C12 cells. Schematic diagrams (A-C) depict effects of scaffold feature size and pore pattern on $\mathrm{C} 2 \mathrm{C} 12$ cell elongation and interconnectivity, where black lines indicate predominant direction of cell elongation with respect to a central pore. Note that similar effects were seen for each pore, but for clarity were shown only for a central pore. Confocal micrographs of 5-day constructs stained for filamentous actin using FITC-phalloidin and for nuclei using DRAQ5, showing cells on the surface of the uppermost strut (D-F) and within the pores of 2:1 CR (D, G), 5:1 CR (E, H), and 2:1 HR (F, I) scaffold designs. In the 5:1 CR design, cell guidance in the PD was provided by 30- $\mu \mathrm{m}$ struts (E) and $250 \times 50 \mu \mathrm{m}$ pores $(\mathrm{H})$, while in the 2:1 HR design, cell-to-cell connections between pores were observed diagonally as well as in the PD and XD directions (F). Scale bars: $20 \mu \mathrm{m}$. Color images available online at www.liebertpub.com/tea

penetration and seeding throughout 2L scaffolds (Fig. 8), and (5) maintenance of neonatal heart cell phenotype in $2 \mathrm{~L}$ constructs (Fig. 8).

An interest in replicating tissue-scale architecture motivated the choice of the two CR designs. Moving from 2:1 CR
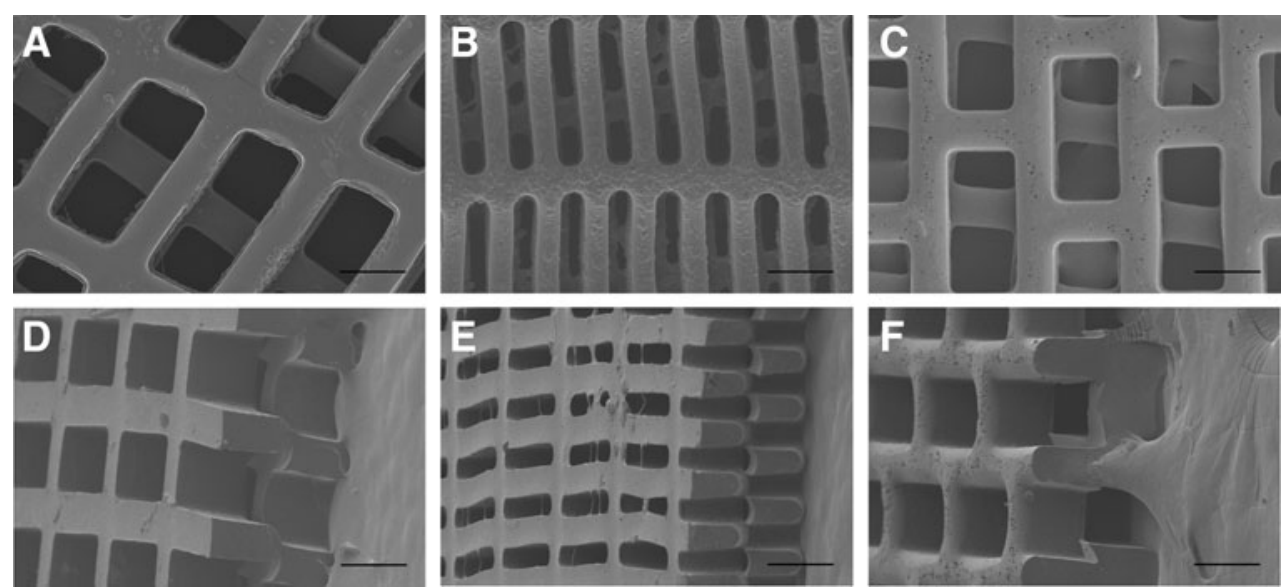

to 5:1 CR, $l$ and $w$ were intentionally reduced toward the tissue scale. As such, comparison of 2:1 vs. 5:1 CR designs offered a potential ability to tease out differences due to scaffold structural features while maintaining scaffold mechanical properties relatively close to each other and to those
FIG. 6. Two-layer (2L) scaffolds with threedimensional (3D) pore microarchitecture were fabricated by offset stacking of $1 \mathrm{~L}$ scaffolds.

Representative scanning electron micrographs of three PGS scaffold designs: 2:1 CR (A, D), 5:1 CR (B, E), and 2:1 HR $(\mathbf{C}, \mathbf{F})$, viewed from above (A-C) or 45 degrees (D-F), show offset stacking along the long pore axis. Scale bars: $200 \mu \mathrm{m}$. 


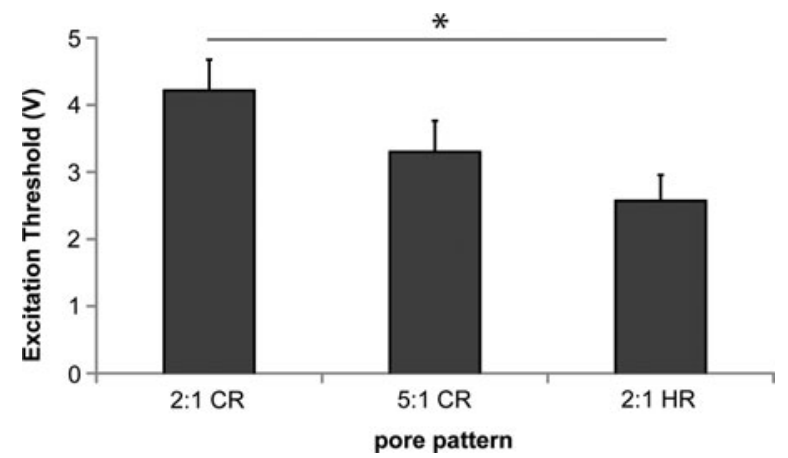

FIG. 7. Scaffold design affected the contractility of heart cells. Excitation threshold (ET, V) shown for heart cells cultured on $2 \mathrm{~L}$ scaffolds for 1 week. Data are mean \pm standard error of at least five independent samples. Significance was asserted at $p<0.05$ (indicated by *) using a one-way analysis of variance (ANOVA) with Tukey's post hoc testing.

of LV. An interest in studying effects of scaffold mechanical properties motivated the comparison of 2:1 CR and 2:1 HR designs. Moving from 2:1 CR to 2:1 HR reduced $E_{X D}$ and increased $r$, offering a potential ability to discover effects due to changes in pore pattern and certain scaffold mechanical properties, since feature sizes were maintained.

New micromolding methods were established for rapid, precise, reproducible production of PGS scaffolds with high aspect ratio of strut height: strut width $(5: 1)$ and thin $(30 \mu \mathrm{m})$ strut width. The silicon-based replica molding method

FIG. 8. Heart cells

distributed throughout depth of $2 \mathrm{~L}$ constructs and expressed a cardiac-specific marker. Full-construct crosssections, cut to a thickness of $60 \mu \mathrm{m}$ and stained with hematoxylin and eosin ( ${ }^{*}$ indicates polymer), show cells throughout the depth of scaffolds of all three designs (A-C, cut in parallel to the long-pore axis; and $\mathbf{B}$, inset, cut in parallel to the shortpore axis). Cells formed a multicellular layer across top struts of 5:1 CR 2L scaffold (B, inset). Representative 3D renderings of $50-\mu \mathrm{m}$-thick stacks taken on a confocal microscope after staining with $\alpha$-actinin (arrowheads indicate sarcomeric banding) indicate cardiomyocyte phenotype in all three scaffold designs: 2:1 CR (D, G), 5:1 CR (H), and 2:1 HR (F, I). Scale bars: $100 \mu \mathrm{m}$ (A-C), $50 \mu \mathrm{m}$ (D-F), and $10 \mu \mathrm{m}$ (G-I). Color images available online at www.liebertpub.com/tea developed and optimized for PGS scaffold production was more precise and high throughput than our previously described laser microablation method. ${ }^{11,20,51}$ Specifically, fabrication by micromolding yielded more precise in-plane scaffold features than could be achieved by current laser microablation techniques, in part due to negligible pore tapering from top to bottom of $150-\mu$ m-thick scaffolds. Micromolding allowed strut widths of $30 \mu \mathrm{m}$ that were not achievable with laser microablation, due to depth-dependent changes in laser intensity. Additionally, minimal pore tapering assisted in maintaining consistent mechanical properties and pore geometry, and enabled a closer match with the numerical predictions on idealized structures. The addition of an RIE step at the end of the silicon mold fabrication process smoothed both the corners and walls of the etched silicon, allowing for more consistent demolding of the PGS scaffolds, which in turn provided the opportunity to demold larger areas and to fabricate higher aspect ratios of feature height versus feature width than previously achieved. ${ }^{51,58,64,65}$ Selecting maltose as the sacrificial layer to coat etched silicon wafers enabled more reliable demolding of PGS scaffolds than a sacrificial layer of sucrose, which was impaired by uncontrollable sucrose crystallization (a result of moisture and humidity or exposure to high temperature). Finally, volumetric dispensing of PGS dissolved in ethanol provided more reliable control over mold filling, scaffold thickness, and thin-film thickness as compared to the previously used method of PGS prepolymer melt casting. ${ }^{51}$

The ability to demold larger areas of scaffolds than are required for in vitro studies is critical as we consider scale-up
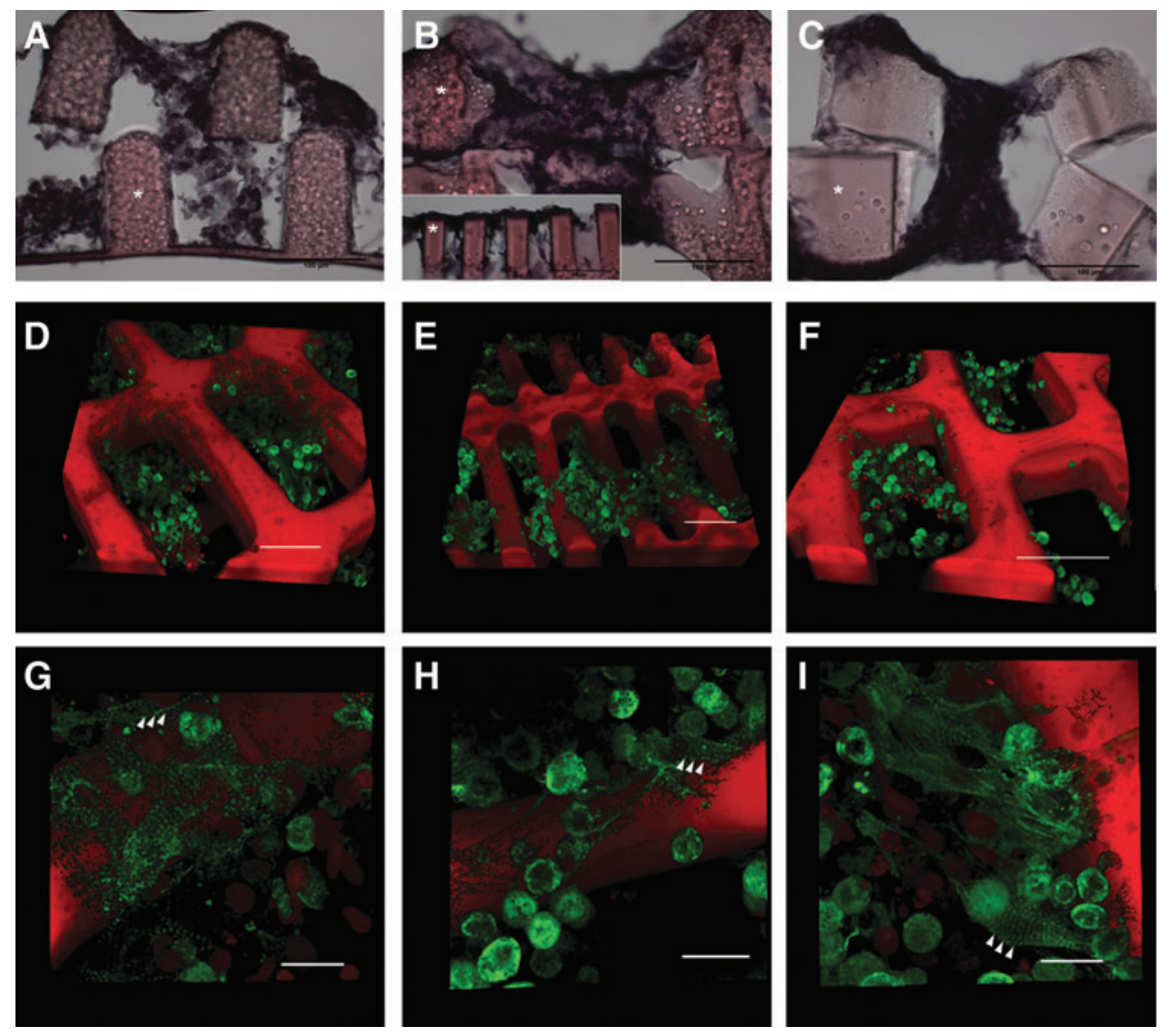
of scaffold fabrication toward anatomical dimensions for future clinical applications. Micromolding of PGS scaffolds yielded very consistent scaffold dimensions and pore shapes over relatively short time periods. The molds used in this study were $20 \times 20 \mathrm{~mm}$, and more than 20 molds could be cast and cured simultaneously, resulting in much greater and faster yield than laser microablation could produce. In addition, molds could be cleaned and reused, facilitating consistent scaffold geometry. While PGS scaffolds fabricated in the present study were purposefully restricted to planar dimensions of $20 \times 20 \mathrm{~mm}$, suitable for in vitro cell culture and mechanical testing, the ability to demold larger areas of scaffolds is critical. One advantage of our replica molding approach is that maximum planar dimensions are limited only by the dimensions of the silicon substrate and mask aligner. In the current study, we used a mask aligner capable of accommodating four- or six-inch-diameter silicon wafers; even larger (eight or twelve inch) wafers are routinely used in semiconductor fabrication. Thickness limitations are also a consideration for scale-up to human myocardial applications. Our design for multilaminar scaffolds was developed to overcome these limitations, and ongoing work will further enhance our capabilities of generating thick cardiac grafts. Importantly, engineered cardiac constructs with thicknesses on the length scale of native myocardium will require microvascular-like networks to sustain the viability of highly metabolically active heart cells. As such, recent studies $^{21,35,67-69}$ have explored a variety of biomaterials and techniques to produce prevascularized grafts with promising results.

The aspect ratio of molded feature height versus feature width for scaffolds was as high as 5:1 (150- $\mu \mathrm{m}$ strut height; $30-\mu \mathrm{m}$ strut width), which exceeded previous reports for replica-molded PGS scaffolds in which the feature heightversus-width ratios were 2:1 or lower. ${ }^{51,58,64,65}$ These highaspect ratio struts in combination with stacking of multiple layers may help to achieve tissue-scale thicknesses for tissue engineering applications, as many more layers would otherwise be needed to achieve the same overall thickness, increasing the chances of misalignment or pore closure resulting from multiple rounds of stacking and laminating. We produced 2L scaffolds with a fully interconnected pore network by a manual stacking process as previously described, ${ }^{20}$ but this was difficult due to the flexibility and deformability of PGS scaffolds with cardiomimetic mechanical properties. In ongoing work, we are exploring more rigorous stacking methodologies to improve pore and strut alignment in multilayered scaffolds.

In consideration of our objective to match scaffold stiffness, anisotropy, and strain-to-failure to cardiac-mimetic values, we undertook uniaxial tensile testing of the fabricated scaffolds. Although $\mathrm{E}_{\mathrm{PD}}$ was higher than physiologic in all three scaffold designs, and $E_{X D}$ higher in both $C R$ designs, we previously showed decreases in accordion-like honeycomb scaffold $E_{\mathrm{PD}}$ and $\mathrm{E}_{\mathrm{XD}}$ both with cyclic mechanical fatiguing and with in vitro culture of heart cells. ${ }^{11}$ It is reasonable to assume that our rectangular pore scaffolds will show qualitatively similar responses to fatigue testing or cell culture as our accordion-like honeycomb scaffolds, resulting in stiffnesses decreasing into a more physiologic range.

Tensile mechanical testing of scaffolds in orthogonal directions justified FE model predictions as a means to select only candidate scaffolds with desired mechanical properties for fabrication. Although FE model predictions overestimated actual values in the PD direction and underestimated empirical values in the XD direction, model trends were consistent. Possible explanations for the minor differences include error during experimental testing, particularly for the 2:1 HR pattern tested in the XD direction, and differences between stiffnesses of PGS scaffolds and stiffnesses of nonporous PGS membranes utilized in our FE simulations, which could in turn be due to potential influences of the mold on local temperatures during curing. Despite the minor discrepancy, we considered the model validated for use with the scaffold pore designs we chose.

The FE model was then used to predict how PGS degradation and loading would be expected to impact scaffold stiffness and anisotropy. All three scaffold designs exhibited decreases in $E_{P D}$ and $E_{X D}$ as a function of decreasing strut width and increasing pore area, which were covaried to approximate the degradation by surface hydrolysis that occurs in vivo ${ }^{43,45}$ and in vitro. ${ }^{44}$ Gradual reduction in scaffold stiffness during scaffold degradation is a primary objective of tissue engineering applications where it is envisioned that regeneration of a mechanically functional, fully biological tissue can gradually replace the mechanical support temporarily contributed by a biodegradable scaffold..$^{26,43}$

The marked increase in anisotropy predicted during simulated degradation of the HR scaffold can be attributed to its architecture, comprising discontinuous struts in the $\mathrm{XD}$ direction and continuous struts in the PD direction. In particular, while $C R$ scaffolds were predicted to respond to $\mathrm{XD}$ loading by tensile extension of XD-oriented struts (Fig. 4D), HR scaffolds were predicted to respond to XD loading primarily by flexural deformation (i.e., bending) of PD-oriented struts (Fig. 4E). These distinct modes of deformation exhibited by the HR-versus-CR scaffolds can account for their distinct changes in effective stiffness predicted in association with simulated degradation. Flexural deformation of the PDoriented struts is theorized to contribute nonlinearly to the effective stiffnesses and the associated anisotropy ratio of the HR scaffold, due to the cubic (i.e., third power) dependence of the strut segment's cross-sectional area moment of inertia on the strut width. ${ }^{63}$ By contrast, tensile deformation of the XD-oriented struts is theorized to contribute only linearly to the effective stiffnesses and associated anisotropy ratio of the CR scaffolds, due to the linear dependence of the strutsegment cross-sectional area on the strut width. Experimental studies of how these two scaffold designs will respond to cyclic fatigue is the subject of ongoing work, not only in vitro but also in vivo where PGS degradation has been shown to occur even more quickly. ${ }^{56}$

In consideration of our objective to provide scaffold pore patterns that enable the formation of a syncytium of muscle cells, we examined $\mathrm{C} 2 \mathrm{C} 12$ cells, which have a propensity to form connections with one another and align along scaffold microstructures. ${ }^{51,70} \mathrm{C} 2 \mathrm{C} 12$ cells formed connections with cells in adjacent pores by proliferating and elongating across intervening struts in all three scaffolds in a design-dependent manner (Fig. 5). Taking scaffold feature size into account, we compared 2:1 CR and 5:1 CR designs, with the latter presenting architectural features closer to tissue scale. The 2:1 CR pores directed cell elongation and interconnectivity in both PD and XD directions, while the 5:1 CR pores 
encouraged relatively more elongation and interconnectivity in the PD direction, possibly due to the smaller pore dimensions and strut widths. Regarding effects of pore pattern and mechanical properties, we compared 2:1 CR and 2:1 HR designs, with the latter providing a higher number of neighboring pores, lower $\mathrm{E}_{\mathrm{XD}}$, and higher $r$. The HR pores promoted $\mathrm{C} 2 \mathrm{C} 12$ cell elongation and interconnectivity in multiple directions, including PD, XD, and even diagonally, suggesting that this elongation outward from the center of the pore was likely directed by the presence of six neighboring pores and cell-to-cell connections formed among them.

We also examined neonatal rat heart cells, which have a propensity to form a syncytium characterized by coordinated, synchronous contraction. Heart cells were cultured on 2L scaffolds bounded by a thin PGS film, thereby increasing the capacity for cell retention and delivery and building scaffold thickness toward the eventual goal of reconstructing full-thickness myocardial defects. ET was significantly lower in the 2:1 HR group as compared to the 2:1 CR group (Fig. 7), suggesting a dependence of construct contractile function on scaffold design. One explanation for this finding is that six neighbor pores enhanced formation of a contractile syncytium; another plausible alternative is that the lower ET in the 2:1 HR scaffold group was due to lower scaffold stiffnesses than 2:1 CR scaffolds, given the initial scaffold mechanical properties measured in this group, predicted scaffold degradation, and the previous finding of reduction in scaffold stiffnesses over 1 week of heart cell culture. ${ }^{11} \mathrm{We}^{11,20,61,62,71}$ and others ${ }^{34,36,72}$ routinely use ET as a measure of contractile function for an engineered cardiac construct, and a reduction in ET has been correlated with increases in contractile force generation $^{34}$ and contractile amplitude ${ }^{34,71}$ in cardiac constructs based on soft scaffold materials. In ongoing studies, we are exploring additional measures of contractile function, including the use of computer-based image analyses, ${ }^{73}$ multielectrode arrays, ${ }^{74}$ optical mapping using voltage- and calcium-sensitive fluorescent dyes, ${ }^{74}$ and force transducers. ${ }^{74}$

Heart cells seeded through the full thickness of the 2L scaffolds and formed contractile, multilayered muscle tissues over 1 week of in vitro culture, showing that 2L scaffolds with interconnected pores $200 \mu \mathrm{m}$ in total thickness allowed heart cells to attach, survive, and form functional connections without perfusion by a bioreactor or another flow device (Fig. 8). The 5:1 CR scaffold was deformed to some degree in 1-week constructs, with struts in the top layer contacting one another in places and closing off access to pores. This scaffold deformation was associated with the formation of a solid, tissue-like layer, one or more cells thick across the top of the scaffold that encouraged cell-to-cell connectivity at the top surface of the construct, but prevented interconnectivity of the two layers. The 5:1 CR scaffold may approach the limit for individual layer height $(100 \mu \mathrm{m})$ compared to strut width $(30 \mu \mathrm{m})$ for PGS scaffolds, as the 2:1 $\mathrm{CR}$ and 2:1 HR with the same layer height and wider struts $(50 \mu \mathrm{m})$ did not deform. Scaffold deformation might be overcome by stacking a greater number of thinner scaffolds, making an automated stacking method an essential next step in reaching tissue-relevant construct thickness.

At 1 week of culture, many cells within scaffolds of all three designs exhibited positive staining for sarcomeric $\alpha$-actinin, a cardiomyocyte marker not found in the cardiac fibroblasts that were also present in the initially seeded population of neonatal rat heart cells. The presence of $\alpha$-actinin demonstrated that 2L PGS scaffolds supported the viability and phenotype of the cultured cardiomyocytes. In addition, the presence of sarcomeric banding in association with spontaneous and stimulated contractions suggested early maturation of some of the neonatal heart cells. In ongoing work, we are exploring electrical stimulation as a means to induce elongation of cardiomyocytes on 2L PGS scaffolds, extending previous demonstrations carried out using other cell culture substrates. ${ }^{61,72}$

The next step for bringing this construct closer to application is validation in a preclinical infarct model. In vivo validation of our approach is being addressed in ongoing studies. One potential limitation of the current study is that target mechanical properties of the PGS scaffolds were chosen as those of normal, not infarcted, myocardium, whereas the optimal mechanical properties of a scaffold for myocardial repair remain unknown. Likewise, an in vivo study by Stuckey et al. ${ }^{56}$ matched PGS membrane mechanical properties to those of normal rat myocardium, and demonstrated that these PGS membranes reduced post-MI hypertrophy in a rodent model in contrast to a stiffer material. In Stuckey et al. $^{56}$ the PGS membranes had a modulus of $300 \mathrm{kPa}$, corresponding to a membrane stiffness of $0.117 \mathrm{~N} / \mathrm{mm}$ (0.67lbs/inch). Clinical studies have shown that a cardiac support device (Acorn CorCap ${ }^{\mathrm{TM}}$ Cardiovascular, Inc.) can limit post-MI remodeling associated with deterioration of cardiac function in humans. $5,9,75$ These CorCap ${ }^{\mathrm{TM}}$ devices had an estimated membrane stiffness of $0.315 \mathrm{~N} / \mathrm{mm}$ (1.8 lbs/inch), based on compliance data in a cardiac-relevant strain range of $10 \%$ to $25 \%$; a modulus was not estimated because material thickness was not provided. ${ }^{75}$ In a recent in vivo study by Fomovsky et al., ${ }^{40}$ anisotropic reinforcement post-MI in a canine model yielded improved systolic function, while isotropic reinforcement did not yield functional improvement, consistent with the predictions of a computational model. While Fomovsky et al. ${ }^{40}$ studied acellular poly(ethylene terephathalate) grafts in vivo, as opposed to the current study of cellularized PGS scaffolds in vitro, their promising results highlight the importance of combining computational modeling and experimentation to address anisotropy in the setting of myocardial regeneration and repair, and support the utility of an inherently flexible technique for the production of anisotropic cardiac grafts.

\section{Conclusion}

2L PGS scaffolds designed based on FE simulations and exhibiting offset, anisotropic, and interconnected pores provided a platform for cell delivery while simultaneously recapitulating the geometry and mechanical properties of normal heart muscle. Herein, a 2L scaffold with a network of fully interconnected pores supported the in vitro development of contractile muscle constructs from neonatal rat heart cells over 1 week of culture. The modular nature of the scaffold and its layer-by-layer assembly provided the ability to extend the scaffold in three dimensions, but especially provided a method to achieve physiologically relevant tissue thickness. The FE model developed in this study may be further manipulated to optimize the beneficial qualities of the scaffolds studied herein. As such, this work not only 
demonstrated several scaffold designs that promoted neonatal rat heart cell culture and contraction in vitro, but also provided the foundation for further computational and empirical investigations of 3D elastomeric scaffolds for cardiac tissue engineering.

\section{Acknowledgments}

This work was funded by the National Heart, Lung, and Blood Institute (NHLBI), Award 1-R01-HL107503 (LEF) and the American Recovery and Reinvestment Act Award 1-R01HL086521 (PI LEF; subaward PI GCE). The content is solely the responsibility of the authors and does not necessarily represent the official views of the NHLBI or NIH. We are indebted to M.D. Guillemette for general advice, J. Wang for help with polymer synthesis and processing, R. Gauvin for help with mechanical testing, E. Vasile for help with microscopy, W. Zhang and M. Brown for help with histology, and S. Jain for technical assistance. We also appreciate the thoughtful comments of B. Larson, M. Kolewe, B. Karikkineth, and X. Ye.

\section{Disclosure Statement}

No competing financial interests exist.

\section{References}

1. Roger, V.L., Go, A.S., Lloyd-Jones, D.M., Benjamin, E.J., Berry, J.D., Borden, W.B., Bravata, D.M., Dai, S., Ford, E.S., Fox, C.S., Fullerton, H.J., Gillespie, C., Hailpern, S.M., Heit, J.A., Howard, V.J., Kissela, B.M., Kittner, S.J., Lackland, D.T., Lichtman, J.H., Lisabeth, L.D., Makuc, D.M., Marcus, G.M., Marelli, A., Matchar, D.B., Moy, C.S., Mozaffarian, D., Mussolino, M.E., Nichol, G., Paynter, N.P., Soliman, E.Z., Sorlie, P.D., Sotoodehnia, N., Turan, T.N., Virani, S.S., Wong, N.D., Woo, D., and Turner, M.B. Heart disease and stroke statistics-2012 update: a report from the American Heart Association. Circulation 125, e2, 2012.

2. Gilboa, S.M., Salemi, J.L., Nembhard, W.N., Fixler, D.E., and Correa, A. Mortality resulting from congenital heart disease among children and adults in the United States, 1999 to 2006/clinical perspective. Circulation 122, 2254, 2010.

3. Zilla, P., Bezuidenhout, D., and Human, P. Prosthetic vascular grafts: wrong models, wrong questions and no healing. Biomaterials 28, 5009, 2007.

4. Chikwe, J., Filsoufi, F., and Carpentier, A.F. Prosthetic valve selection for middle-aged patients with aortic stenosis. Nat Rev Cardiol 7, 711, 2010.

5. Mann, D.L., Kubo, S.H., Sabbah, H.N., Starling, R.C., Jessup, M., Oh, J.K., and Acker, M.A. Beneficial effects of the CorCap cardiac support device: five-year results from the Acorn Trial. J Thorac Cardiovasc Surg 143, 1036, 2011.

6. Tang, D., Yang, C., Geva, T., Gaudette, G., and del Nido, P.J. Multi-physics MRI-based two-layer fluid-structure interaction anisotropic models of human right and left ventricles with different patch materials: cardiac function assessment and mechanical stress analysis. Comput Struct 89, 1059, 2011.

7. Gorman, R., Jackson, B., Burdick, J., and Gorman, J. Infarct restraint to limit adverse ventricular remodeling. J Cardiovasc Transl Res 4, 73, 2011.

8. Tang, D., Yang, C., Geva, T., Gaudette, G., and Del Nido, P.J. Effect of patch mechanical properties on right ventricle function using MRI-based two-layer anisotropic models of human right and left ventricles. Comput Model Eng Sci 56, 113, 2010.

9. Atluri, P., and Acker, M.A. Diastolic ventricular support with cardiac support devices: an alternative approach to prevent adverse ventricular remodeling. Heart Fail Rev Apr 15, 2012. [Epub ahead of print]; DOI: 10.1007/s10741-0129312-4.

10. Bursac, N., Papadaki, M., Cohen, R.J., Schoen, F.J., Eisenberg, S.R., Carrier, R., Vunjak-Novakovic, G., and Freed, L.E. Cardiac muscle tissue engineering: toward an in vitro model for electrophysiological studies. Am J Physiol Heart Circ Physiol 277, H433, 1999.

11. Engelmayr, G.C., Jr., Cheng, M., Bettinger, C.J., Borenstein, J.T., Langer, R., and Freed, L.E. Accordion-like honeycombs for tissue engineering of cardiac anisotropy. Nat Mater 7, 1003, 2008.

12. Lesman, A., Habib, M., Caspi, O., Gepstein, A., Arbel, G., Levenberg, S., and Gepstein, L. Transplantation of a tissueengineered human vascularized cardiac muscle. Tissue Eng Part A 16, 115, 2010.

13. Eschenhagen, T., Fink, C., Remmers, U., Scholz, H., Wattchow, J., Woil, J., Zimmermann, W., Dohmen, H.H., Schafer, H., Bishopric, N., Wakatsuki, T., and Elson, E. Three-dimensional reconstitution of embryonic cardiomyocytes in a collagen matrix: a new heart model system. FASEB J 11, 683, 1997.

14. Davis, M.E., Hsieh, P.C., Takahashi, T., Song, Q., Zhang, S., Kamm, R.D., Grodzinsky, A.J., Anversa, P., and Lee, R.T. Local myocardial insulin-like growth factor 1 (IGF-1) delivery with biotinylated peptide nanofibers improves cell therapy for myocardial infarction. PNAS 103, 8155, 2006.

15. Ruvinov, E., Leor, J., and Cohen, S. The promotion of myocardial repair by the sequential delivery of IGF-1 and HGF from an injectable alginate biomaterial in a model of acute myocardial infarction. Biomaterials 32, 565, 2011.

16. Liau, B., Christoforou, N., Leong, K.W., and Bursac, N. Pluripotent stem cell-derived cardiac tissue patch with advanced structure and function. Biomaterials 32, 9180, 2011.

17. Serrao, G.W., Turnbull, I.C., Ancukiewicz, D., Kim do, E., Kao, E., Cashman, T.J., Hadri, L., Hajjar, R.J., and Costa, K.D. Myocyte-depleted engineered cardiac tissues support therapeutic potential of mesenchymal stem cells. Tissue Eng Part A 18, 1322, 2012.

18. Radisic, M., Yang, L., Boublik, J., Cohen, R.J., Langer, R., Freed, L.E., and Vunjak-Novakovic, G. Medium perfusion enables engineering of compact and contractile cardiac tissue. Am J Physiol Heart Circ Physiol 286, H507, 2004.

19. Boublik, J., Park, H., Radisic, M., Tognana, E., Chen, F., Pei, M., Vunjak-Novakovic, G., and Freed, L.E. Mechanical properties and remodeling of hybrid cardiac constructs made from heart cells, fibrin, and biodegradable, elastomeric knitted fabric. Tissue Eng 11, 1122, 2005.

20. Park, H., Larson, B.L., Guillemette, M.D., Jain, S.R., Hua, C., Engelmayr, G.C., Jr., and Freed, L.E. The significance of pore microarchitecture in a multi-layered elastomeric scaffold for contractile cardiac muscle constructs. Biomaterials 32, 1856, 2011.

21. Lesman, A., Koffler, J., Atlas, R., Blinder, Y.J., Kam, Z., and Levenberg, S. Engineering vessel-like networks within multicellular fibrin-based constructs. Biomaterials 32, 7856, 2011.

22. L'Heureux, N., Dusserre, N., Konig, G., Victor, B., Keire, P., Wight, T.N., Chronos, N.A.F., Kyles, A.E., Gregory, C.R., Hoyt, G., Robbins, R.C., and McAllister, T.N. Human tissue- 
engineered blood vessels for adult arterial revascularization. Nat Med 12, 361, 2006.

23. Baar, K., Birla, R., Boluyt, M.O., Borschel, G.H., Arruda, E.M., and Dennis, R.G. Self-organization of rat cardiac cells into contractile 3-D cardiac tissue. FASEB J 19, 275, 2005.

24. Stevens, K.R., Kreutziger, K.L., Dupras, S.K., Korte, F.S., Regnier, M., Muskheli, V., Nourse, M.B., Bendixen, K., Reinecke, H., and Murry, C.E. Physiological function and transplantation of scaffold-free and vascularized human cardiac muscle tissue. Proc Natl Acad Sci U S A 106, 16568, 2009.

25. Ott, H.C., Matthiesen, T.S., Goh, S.K., Black, L.D., Kren, S.M., Netoff, T.I., and Taylor, D.A. Perfusion-decellularized matrix: using nature's platform to engineer a bioartificial heart. Nat Med 14, 213, 2008.

26. Langer, R., and Vacanti, J.P. Tissue engineering. Science 260, 920, 1993.

27. Zimmermann, W.H., Melnychenko, I., Wasmeier, G., Didie, M., Naito, H., Nixdorff, U., Hess, A., Budinsky, L., Brune, K., Michaelis, B., Dhein, S., Schwoerer, A., Ehmke, H., and Eschenhagen, T. Engineered heart tissue grafts improve systolic and diastolic function in infarcted rat hearts. Nat Med 12, 452, 2006.

28. Dahl, S.L.M., Kypson, A.P., Lawson, J.H., Blum, J.L., Strader, J.T., Li, Y., Manson, R.J., Tente, W.E., DiBernardo, L., Hensley, M.T., Carter, R., Williams, T.P., Prichard, H.L., Dey, M.S., Begelman, K.G., and Niklason, L.E. Readily available tissueengineered vascular grafts. Sci Transl Med 3, 68ra9, 2011.

29. Hibino, N., Shin'oka, T., Matsumura, G., Ikada, Y., and Kurosawa, $\mathrm{H}$. The tissue-engineered vascular graft using bone marrow without culture. J Thorac Cardiovasc Surg 129, 1064, 2005.

30. McAllister, T.N., Maruszewski, M., Garrido, S.A., Wystrychowski, W., Dusserre, N., Marini, A., Zagalski, K., Fiorillo, A., Avila, H., Manglano, X., Antonelli, J., Kocher, A., Zembala, M., Cierpka, L., de la Fuente, L.M., and L'Heureux, $\mathrm{N}$. Effectiveness of haemodialysis access with an autologous tissue-engineered vascular graft: a multicentre cohort study. Lancet 373, 1440, 2009.

31. Dohmen, P.M., Lembcke, A., Holinski, S., Pruss, A., and Konertz, W. Ten years of clinical results with a tissueengineered pulmonary valve. Ann Thorac Surg 92, 1308, 2011.

32. Freed, L.E., Engelmayr, G.C., Jr., Borenstein, J.T., Moutos, F.T., and Guilak, F. Advanced material strategies for tissue engineering scaffolds. Adv Mater 21, 3410, 2009.

33. Jacot, J.G., McCulloch, A.D., and Omens, J.H. Substrate stiffness affects the functional maturation of neonatal rat ventricular myocytes. Biophys J 95, 3479, 2008.

34. Bhana, B., Iyer, R.K., Chen, W.L., Zhao, R., Sider, K.L., Likhitpanichkul, M., Simmons, C.A., and Radisic, M. Influence of substrate stiffness on the phenotype of heart cells. Biotechnol Bioeng 105, 1148, 2010.

35. Vunjak-Novakovic, G., Lui, K.O., Tandon, N., and Chien, K.R. Bioengineering heart muscle: a paradigm for regenerative medicine. Annu Rev Biomed Eng 13, 245, 2011.

36. Reis, L.A., Chiu, L.L., Liang, Y., Hyunh, K., Momen, A., and Radisic, M. A peptide-modified chitosan-collagen hydrogel for cardiac cell culture and delivery. Acta Biomater 8, 1022, 2011.

37. Fomovsky, G.M., Rouillard, A.D., and Holmes, J.W. Regional mechanics determine collagen fiber structure in healing myocardial infarcts. J Mol Cell Cardiol 52, 1083, 2012.

38. Holmes, J.W., Borg, T.K., and Covell, J.W. Structure and mechanics of healing myocardial infarcts. Annu Rev Biomed Eng 7, 223, 2005.
39. Fomovsky, G.M., J.R., M., Ailawadi, G., and Holmes, J.W. Model-based design of mechanical therapies for myocardial infarction. J Cardiovasc Transl Res 4, 82, 2011.

40. Fomovsky, G.M., Clark, S.A., Parker, K.M., Ailawadi, G., and Holmes, J.W. Anisotropic reinforcement of acute anteroapical infarcts improves pump function. Circ Heart Fail 5, 515, 2012.

41. Wang, Y., Ameer, G.A., Sheppard, B.J., and Langer, R. A tough biodegradable elastomer. Nat Biotechnol 20, 602, 2002.

42. Rai, R., Tallawi, M., Grigore, A., and Boccaccini, A.R. Synthesis, properties and biomedical applications of poly(glycerol sebacate) (PGS): a review. Prog Polym Sci 37, 1051, 2012.

43. Wang, Y., Kim, Y.M., and Langer, R. In vivo degradation characteristics of poly(glycerol sebacate). J Biomed Mater Res 66A, 192, 2003.

44. Pomerantseva, I., Krebs, N., Hart, A., Neville, C.M., Huang, A.Y., and Sundback, C.A. Degradation behavior of poly(glycerol sebacate). J Biomed Mater Res A 91, 1038, 2009.

45. Sundback, C.A., Shyu, J.Y., Wang, Y., Faquin, W.C., Langer, R.S., Vacanti, J.P., and Hadlock, T.A. Biocompatibility analysis of poly(glycerol sebacate) as a nerve guide material. Biomaterials 26, 5454, 2005.

46. Motlagh, D., Yang, J., Lui, K.Y., Webb, A.R., and Ameer, G.A. Hemocompatibility evaluation of poly(glycerol-sebacate) in vitro for vascular tissue engineering. Biomaterials 27, 4315, 2006.

47. Chen, Q.Z., Bismarck, A., Hansen, U., Junaid, S., Tran, M.Q., Harding, S.E., Ali, N.N., and Boccaccini, A.R. Characterisation of a soft elastomer poly(glycerol sebacate) designed to match the mechanical properties of myocardial tissue. Biomaterials 29, 47, 2008.

48. Kemppainen, J.M. and Hollister, S.J. Tailoring the mechanical properties of 3D-designed poly(glycerol sebacate) scaffolds for cartilage applications. J Biomed Mater Res 94, 9, 2010.

49. Radisic, M., Park, H., Chen, F., Salazar-Lazzaro, J.E., Wang, Y., Dennis, R.G., Langer, R., Freed, L.E., and VunjakNovakovic, G. Biomimetic approach to cardiac tissue engineering: oxygen carriers and channeled scaffolds. Tissue Eng 12, 2077, 2006.

50. Crapo, P.M., and Wang, Y. Hydrostatic pressure independently increases elastin and collagen co-expression in smalldiameter engineered arterial constructs. J Biomed Mater Res A 96A, 673, 2011.

51. Guillemette, M.D., Park, H., Hsiao, J.C., Jain, S.R., Larson, B.L., Langer, R., and Freed, L.E. Combined technologies for microfabricating elastomeric cardiac tissue engineering scaffolds. Macromol Biosci 10, 1330, 2010.

52. Jean, A. and Engelmayr, G.C., Jr. Finite element analysis of an accordion-like honeycomb scaffold for cardiac tissue engineering. J Biomech 43, 3035, 2010.

53. Jean, A. and Engelmayr, G.C. Anisotropic collagen fibrillogenesis within microfabricated scaffolds: implications for biomimetic tissue engineering. Adv Healthc Mater 1, 112, 2012.

54. Radisic, M., Park, H., Martens, T.P., Salazar-Lazaro, J.E., Geng, W., Wang, Y., Langer, R., Freed, L.E., and VunjakNovakovic, G. Pre-treatment of synthetic elastomeric scaffolds by cardiac fibroblasts improves engineered heart tissue. J Biomed Mater Res 86A, 713, 2008.

55. Chen, Q.Z., Ishii, H., Thouas, G.A., Lyon, A.R., Wright, J.S., Blaker, J.J., Chrzanowski, W., Boccaccini, A.R., Ali, N.N., Knowles, J.C., and Harding, S.E. An elastomeric patch de- 
rived from poly(glycerol sebacate) for delivery of embryonic stem cells to the heart. Biomaterials 31, 3885, 2010.

56. Stuckey, D.J., Ishii, H., Chen, Q.Z., Boccaccini, A.R., Hansen, U., Carr, C.A., Roether, J.A., Jawad, H., Tyler, D.J., Ali, N.N., Clarke, K., and Harding, S.E. Magnetic resonance imaging evaluation of remodeling by cardiac elastomeric tissue scaffold biomaterials in a rat model of myocardial infarction. Tissue Eng Part A 16, 3395, 2010.

57. Wang, J., Bettinger, C.J., Langer, R.S., and Borenstein, J.T. Biodegradable microfluidic scaffolds for tissue engineering from amino alcohol-based poly(ester amide) elastomers. Organogenesis 6, 212, 2010.

58. Neeley, W.L., Redenti, S., Klassen, H., Tao, S., Desai, T., Young, M.J., and Langer, R. A microfabricated scaffold for retinal progenitor cell grafting. Biomaterials 29, 418, 2008.

59. Rasband, W. ImageJ. 1.45s ed. Bethesda, MD: National Institutes of Health, 2011.

60. Naito, H., Melnychenko, I., Didie, M., Schneiderbanger, K., Schubert, P., Rosenkranz, S., Eschenhagen, T., and Zimmermann, W.H. Optimizing engineered heart tissue for therapeutic applications as surrogate heart muscle. Circulation 114, I72, 2006.

61. Radisic, M., Park, H., Shing, H., Consi, T., Schoen, F.J., Langer, R., Freed, L.E., and Vunjak-Novakovic, G. Functional assembly of engineered myocardium by electrical stimulation of cardiac myocytes cultured on scaffolds. PNAS 101, 18129, 2004.

62. Cheng, M., Moretti, M., Engelmayr, G.C., and Freed, L.E. Insulin-like growth factor-I and slow, bi-directional perfusion enhance the formation of tissue-engineered cardiac grafts. Tissue Eng Part A 15, 645, 2009.

63. Engelmayr, G.C., Jr., Papworth, G.D., Watkins, S.C., Mayer, J.E., Jr., and Sacks, M.S. Guidance of engineered tissue collagen orientation by large-scale scaffold microstructures. J Biomech 39, 1819, 2006.

64. Fidkowski, C., Kaazempur-Mofrad, M.R., Borenstein, J., Vacanti, J.P., Langer, R., and Wang, Y. Endothelialized microvasculature based on a biodegradable elastomer. Tissue Eng 11, 302, 2005.

65. Bettinger, C.J., Weinberg, E.J., Kulig, K.M., Vacanti, J.P., Wang, Y., Borenstein, J.T., and Langer, R. Three-dimensional microfluidic tissue-engineering scaffolds using a flexible biodegradable polymer. Adv Mater 18, 165, 2006.

66. Nawroth, J.C., Lee, H., Feinberg, A.W., Ripplinger, C.M., McCain, M.L., Grosberg, A., Dabiri, J.O., and Parker, K.K. A tissue-engineered jellyfish with biomimetic propulsion. Nat Biotechnol 30, 792, 2012.

67. Lesman, A., Gepstein, L., and Levenberg, S. Vascularization shaping the heart. Ann NY Acad Sci 1188, 46, 2010.

68. Wong, K.H., Chan, J.M., Kamm, R.D., and Tien, J. Microfluidic models of vascular functions. Annu Rev Biomed Eng 14, 205, 2012.

69. Miller, J.S., Stevens, K.R., Yang, M.T., Baker, B.M., Nguyen, D.H., Cohen, D.M., Toro, E., Chen, A.A., Galie, P.A., Yu, X., Chaturvedi, R., Bhatia, S.N., and Chen, C.S. Rapid casting of patterned vascular networks for perfusable engineered three-dimensional tissues. Nat Mater 11, 768, 2012.

70. Charest, J.L., Garcia, A.J., and King, W.P. Myoblast alignment and differentiation on cell culture substrates with microscale topography and model chemistries. Biomaterials 28, 2202, 2007.

71. Cheng, M.Y., Park, H., Engelmayr, G.C., Moretti, M., and Freed, L.E. Effects of regulatory factors on engineered cardiac tissue in vitro. Tissue Eng 13, 2709, 2007.

72. Tandon, N., Cannizzaro, C., Chao, P.H., Maidhof, R., Marsano, A., Au, H.T., Radisic, M., and Vunjak-Novakovic, G. Electrical stimulation systems for cardiac tissue engineering. Nat Protoc 4, 155, 2009.

73. Shim, J., Grosberg, A., Nawroth, J.C., Parker, K.K., and Bertoldi, K. Modeling of cardiac muscle thin films: prestretch, passive and active behavior. J Biomech 45, 832, 2012.

74. Liau, B., Zhang, D., and Bursac, N. Functional cardiac tissue engineering. Regenerative Med 7, 187, 2012.

75. Walsh, R.G. Design and features of the Acorn CorCap cardiac support device: the concept of passive mechanical diastolic support. Heart Fail Rev 10, 101, 2005.

Address correspondence to: Lisa E. Freed, $M D, P h D$ Microsystems Development Group Charles Stark Draper Laboratory and MIT-Affiliate 555 Technology Square-Mail Stop 32 Cambridge, MA 02139-4307

E-mail: lfreed@draper.com; lfreed@mit.edu

Received: May 30, 2012

Accepted: October 15, 2012

Online Publication Date: November 26, 2012 